\title{
Punching shear strengthening of flat slabs with CFRP on grooves (EBROG) and external rebars sticking in grooves
}

\author{
Rojin Azizi ${ }^{1}$. Sayed Behzad Talaeitaba ${ }^{1}$
}

Received: 29 January 2018 / Accepted: 1 February 2019 / Published online: 18 February 2019

(C) The Author(s) 2019

\begin{abstract}
The main objective of this study is strengthening of flat slabs in punching shear with a new model. For this purpose 15 numerical samples include a control and 14 strengthened defined and nonlinearly analyzed up to failure. The strengthening method is new method of grooving in two orthogonal direction ( $x$ and $y$ axes of slab plan) and then mounting the external bars (sticking) in one direction and FRP in EBROG (externally bonded reinforcement on groove) method in another direction. The results showed the great efficiency of the method so that the punching shear capacity of strengthened samples increased between 28 and $62 \%$ compare to control one. Also the mode of failure changed in strengthened specimens from shear to flexure-shear and the punching critical area was broader and developed from the loading point. In the grooving method the sticking bars yielded in all specimens and the FRP tensile strain was closer to rupture strain compared to EBR.
\end{abstract}

Keywords Punching shear $\cdot$ Strengthening $\cdot$ Grooving $\cdot$ EBROG $\cdot$ EBRIG $\cdot$ FRP

\section{Introduction}

Flat slab is one of the most widely used types of roof systems. Creating relatively large spans, lower thickness than other structural systems and the ease of implementation of this type of roof in different architectures and work conditions are the advantages of this structural system. Due to the absence of a strong member such as the beam at the junction of flat slab and column, all loads applied on the floor should be passed through the slab-column connection that creates a complex distribution of forces. Moment transfer phenomenon will also add to the existing complexity. Punching shear and ensuring that there is no punching failure, is an important option that should be considered in the course of design. This force tends to leave a peripheral diameter crack in the form of a truncated cone for the circular cross-section of column and a truncated pyramid for the rectangular cross-section of column. Skew angle of the crack in punching shear is between $25^{\circ}$ and $45^{\circ}$ which is usually assumed as equal to $45^{\circ}$ (Park and Paulay 2009). Shear failure is a brittle failure with limited displacements and

Sayed Behzad Talaeitaba

talaeetaba@iaukhsh.ac.ir

1 Civil Department, Azad Islamic University, Khomeinishahr Branch, Po. Box 81475-119 Khomeinishahr, Isfahan, Iran sudden reduction in load bearing capacity and based on the importance of the roof's load bearing capacity in terms of gravity and earthquake, this failure should be strictly avoided (ACI 2014; Megally and Ghali 1994).

Many factors affect the slab-column connection mechanism the most important of which include the reinforcement and the slab thickness. In this field the studies and graphs by Menetrey (2002) are mentioned.

There are several methods to strengthen the punching shear studied by researchers including installing the beam at the tensile side of slab near the column, putting the stud in the direction perpendicular to the slab plane to deal with shear (El-Salakawy et al. 2003), the use of metal sheets at the sides of the slab (Ebead and Marzouk 2002) and the use of various FRP composites strengthening (Harajli and Soudki 2003; Binici and Bayark 2003; Meisami et al. 2012, 2014; Hajihashemi et al. 2011). Rapid separation of the composite from the concrete surface after its connection during load bearing is the major problem in using this material to strengthening concrete structures (premature failure due to debonding). Therefore, before connecting FRP composite to the concrete surface the surface preparation is done to strengthen it, however concrete surface preparation has problems such as implementation cost, environmental pollution and so on (Hajihashemi et al. 2011; Sharaky et al. 2012). Based on the studies conducted in Isfahan University of 
Technology in the past few years, the new grooving method is introduced as a suitable method to replace surface preparation and is followed by good experimental results that the two new externally bonded reinforcement on grooves (EBROG) and externally bonded reinforcement in grooves (EBRIG) methods have developed and evaluated to install composite used to reinforce the beam (Mostofinejad and Mahmoudabadi 2010; Mostofinejad and Hajrasouliha 2011; Mostofinejad and Shameli 2013). The present study aims to investigate the possibility of flat slab strengthening against punching shear by grooving and connecting horizontal bars inside the grooves (alone or in combination with FRP sheets in orthogonal direction). For this purpose 15 numerical models have been simulated. All specimens were slabs with dimensions $1000 \times 1000 \times 100 \mathrm{~mm}$ that included a control specimen without any shear reinforcement against punching shear; 14 specimens were strengthened against the punching shear by the mentioned method. The specimens were analyzed nonlinearly under concentrated load at the middle of span of simply-supported slab until the failure.

\section{Modeling and nonlinear analysis validation in software}

According to this research process that includes modeling and nonlinear analysis of slab, the FRP (EBR or EBROG) strengthened slab and the EBRIG strengthened slab, in all above models first modeling has been validated; accordingly the mentioned modeling has been compared with the experimental specimens of other researchers. Here the validations are presented in those three parts.

\section{Slab modeling validation}

To study slab modeling validation a strengthened concrete tested by Agbossou et al. (2013) has been modeled. Square slabs in that study had the dimensions of $1250 \times 1250 \mathrm{~mm}$ with a thickness of $100 \mathrm{~mm}$. To prevent bending failure and punching shear failure in the above-mentioned study, high steel to concrete ratio $(\rho)$ has been used. Slabs have placed on four simple linear support at the edges. Loading has been applied by hydraulic jacks topically on a plate with the dimensions of $100 \times 100 \mathrm{~mm}$. Mechanical properties of the materials used in modeling are presented in Table 1, also the slab meshing is presented in Fig. 1.

In non-linear analysis the displacement controlled load was applied on all slab specimens on a steel sheet with dimensions $100 \times 100 \mathrm{~mm}$ placed at the middle span of slab. The support according to the Fig. 1a is considered linearly in four sides of the slab near the edges and it is tied up along the applied displacement. In ABAQUS the 8-node C3D8R element and concrete damage plasticity material in
Table 1 Properties of concrete and steel for verified slabs (Agbossou et al. 2008)

\begin{tabular}{lclll}
\hline & $\begin{array}{l}\text { Elastic } \\
\text { modulus } \\
(\mathrm{GP})\end{array}$ & $\begin{array}{l}\text { Poisson's } \\
\text { ratio }\end{array}$ & $\begin{array}{l}\text { Tensile fail- } \\
\text { ure stresses } \\
(\mathrm{MPa})\end{array}$ & $\begin{array}{l}\text { Crushing } \\
\text { failure stresses } \\
(\mathrm{MPa})\end{array}$ \\
\hline Concrete & 30 & 0.2 & 3.5 & 35.4 \\
Steel & 200 & 0.3 & 500 & 500 \\
\hline
\end{tabular}

the predefined material library of the software have been used to model concrete. Plasticity parameters to determine the nonlinear concrete behavior are presented as the mentioned parameters in ABAQUS:

Dilation angle $=36$, eccentricity $=0.1, \mathrm{fb} 0 / \mathrm{fc} 0=1.16$, $k=0.667$, viscosity parameter $=0.0001$. These values were obtained based on software's help and testing and revising to achieve the desirable convergence (ABAQUS 2013). To model the behavior of the reinforcement the full elastic-plastic and the T3D2 two-node rod element was used. ABAQUS/Standard solver is used for modeling analysis and Static-General analysis is applied for solution. Analyses in the General part could calculate structural linear and nonlinear response (ABAQUS 2013).

After nonlinear analysis of the specimen first the loadslab center displacement curve was extracted by the software and is compared with the experimental curve (Fig. 2, $\mathrm{R} 0$ and R1). It should be mentioned that R0 and R1, were the names of experimental specimens in the experimental study of reference (Agbossou et al. 2013). As this figure shows the results of the software are in good agreement with the experimental results. SDEG option used to observe the crack form in nonlinear analysis which is compared with the experimental specimen's crack as shown in Fig. 3. The form of damaged elements in Fig. 3-b shows the punching shear damage and is in good agreement with experiments (Fig. 3-a).

After the validation of nonstrengthened slab modeling and verification of its FEM results, to validate the FRP-reinforced slab modeling the $\mathrm{R} 1$ specimen in Agbossou has been analyzed by nonlinear analysis. In that study to strengthen this specimen strips with the width of $50 \mathrm{~mm}$ and a thickness of $1 \mathrm{~mm}$ have been used with $150 \mathrm{~mm}$ distance as EBR. FRP elastic behavior has been defined by a lamina material. In this case it is necessary to determine the modulus of elasticity along the fiber and in perpendicular direction to it, Poisson's ratio and shear modulus in different directions (Table 2). The four node membrane elements or S4R shell have been used to model them. Other cases such as concrete modeling, reinforcement and supports were as same as control specimen.

By comparing the load-displacement curve (Fig. 2) it is observed that the FEM modeling is capable to validate the behavior of strengthened slab with FRP in EBR method. 


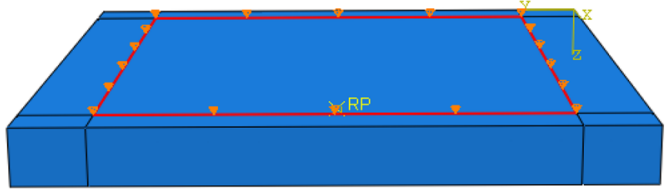

(b)

Fig. 1 a Typical mesh, a boundary condition of slab modeling

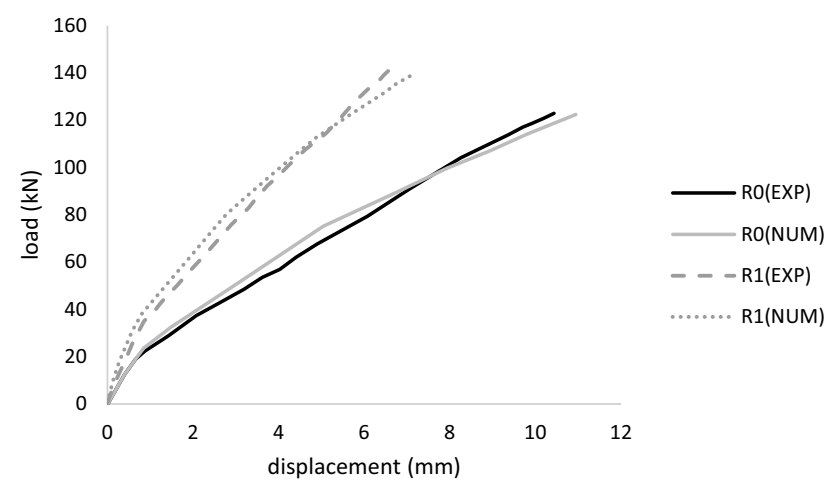

Fig. 2 Comparison of numerical and experimental load displacement curve for nonstrengthened slab

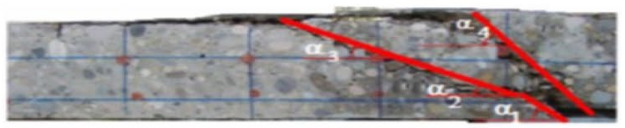

(c) reinforced slab (sample R1)

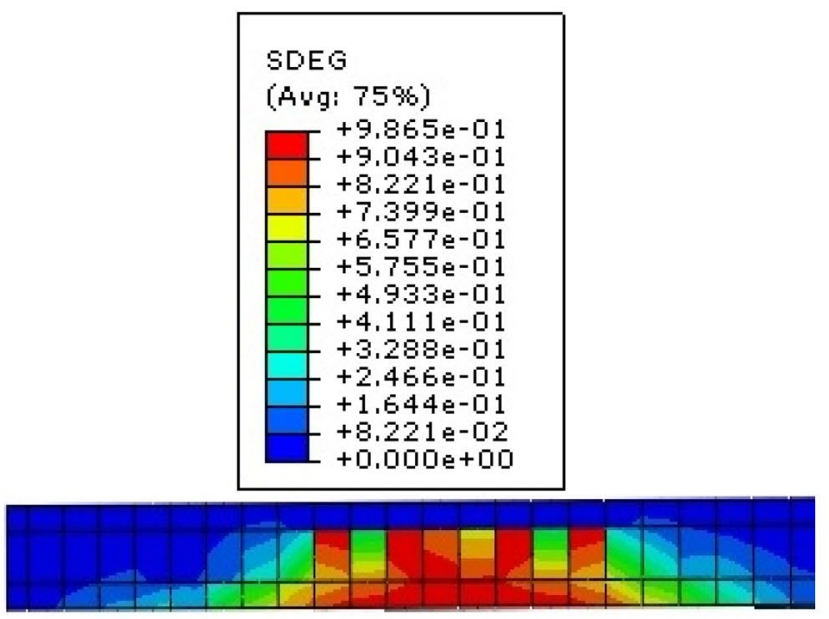

(d) R1 numerical model

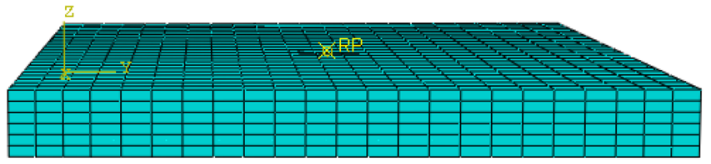

(a)

Strengthening by CFRP sheets has increased the flexural stiffness of the specimens and also increases the load bearing capacity and rupture surfaces have transferred to the outside of the reinforced zone in the strengthened specimen and the reinforced zone remains intact. Therefore, the use of FRP sheets attached to the slab tensile surface is an effective method to strengthen the flat slab systems existing against punching.

The failure of the concrete slab is presented in the analytical model in Fig. 3-d which is in a good agreement with the experimental specimens (Fig. 3-c).

As is clear from Fig. 4, the FRP sheet has not reached its ultimate capacity in the specimen and the low final strain in this specimen indicates the premature separation of the sheet and lack of reaching the final capacity. This result has been observed in both of numerical analysis of

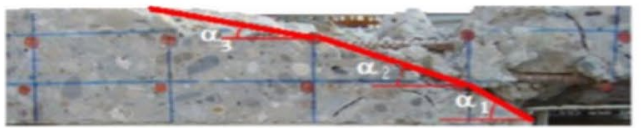

(a)

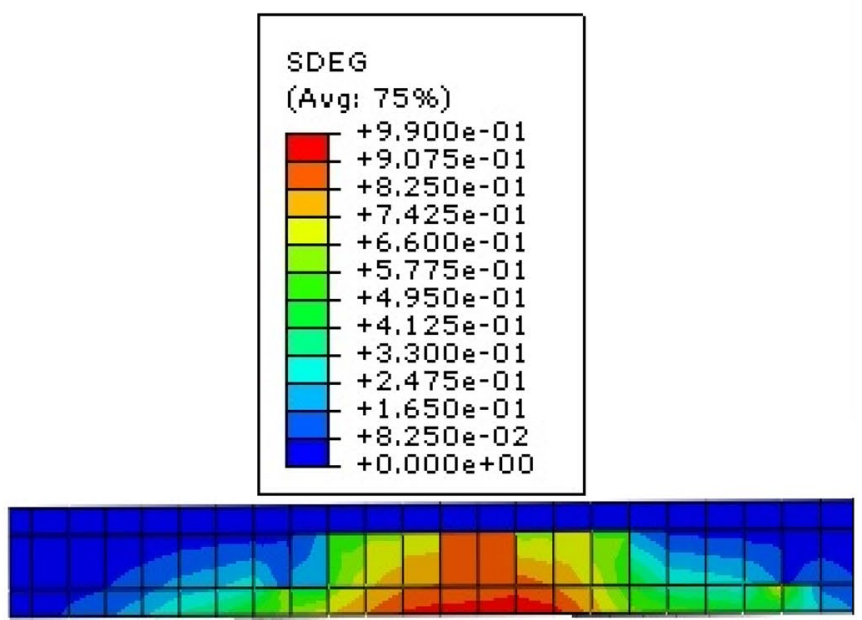

(b) R0 numerical mpdel

Fig. 3 Cracks in slabs' cross-section (numerical vs experimental) 
current study and experimental study of reference (Agbossou et al. 2013).

\section{Grooving method modeling validation}

To validate this part of modeling the beam strengthened by grooving tested by Mostofinejad and Shameli (2013) is modeled in ABAQUS. In Fig. 5 the dimensions of the modeled beam and beam's cross section and groove dimensions are shown. FRP sheet had the length and width of 850 and $100 \mathrm{~mm}$ and the alignment of the fiber was in the longitudinal axis of the beam. The 4-point bending test was done on the beam (Mostofinejad and Shameli 2013). Here the specimens EBROG-1L and EBRIG-1L of the reference (Mostofinejad and Shameli 2013) were modeled in ABAQUS. To simulate the phenomenon of separation between the layers,

Table 2 Mechanical properties of FRP composite (Agbossou et al. 2013)

\begin{tabular}{lllllllllll}
\hline Fiber & $E_{x}(\mathrm{GPa})$ & $E_{y}(\mathrm{GPa})$ & $E_{z}(\mathrm{GPa})$ & $\mathrm{Fu}(\mathrm{MPa})$ & $\gamma_{x y}$ & $\gamma_{y z}$ & $\gamma_{x z}$ & $G_{x y}(\mathrm{GPa})$ & $G_{y z}(\mathrm{GPa})$ & $\mathrm{FG}$ \\
$x z$ & $(\mathrm{GPa})$ \\
\hline CFRP & 70 & 10 & 10 & 925 & 0.22 & 0.3 & 0.22 & 8 & 4.7 & 8 \\
\hline
\end{tabular}

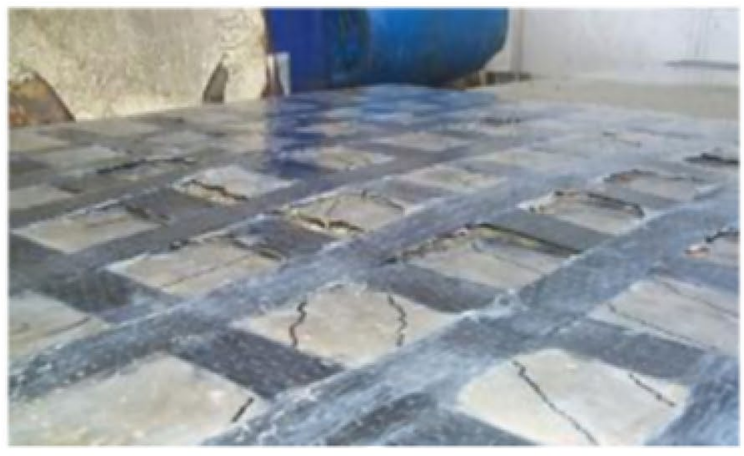

(b)
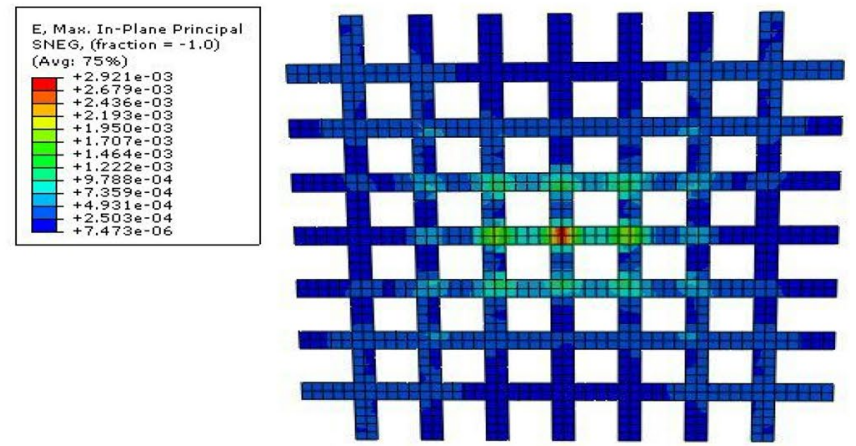

(a)

Fig. 4 Strain distribution in lengthof FRP sheets; a numerical, $\mathbf{b}$ experimental
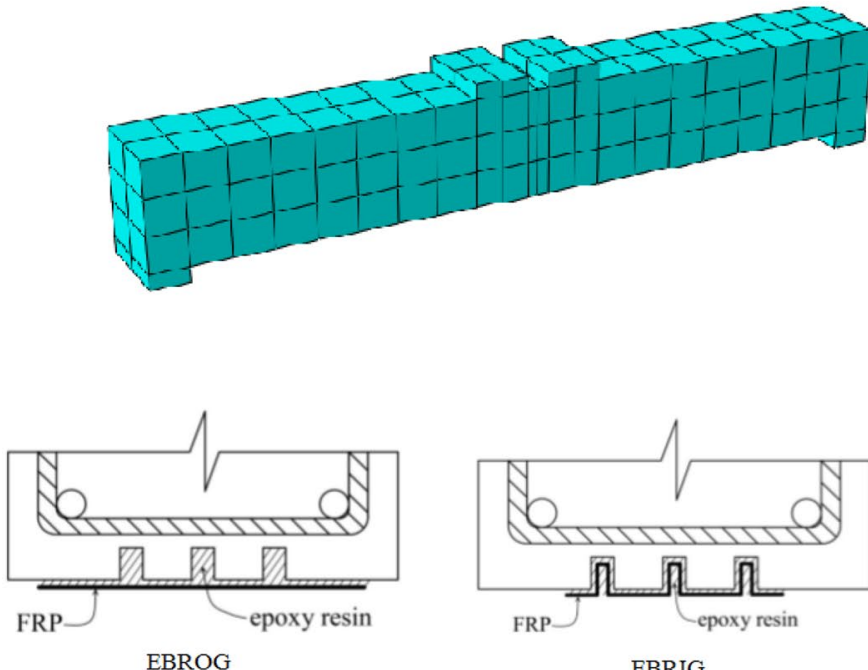

(c)

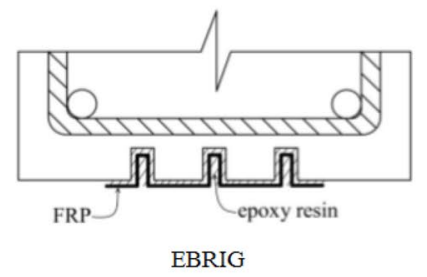

(d)

(c)

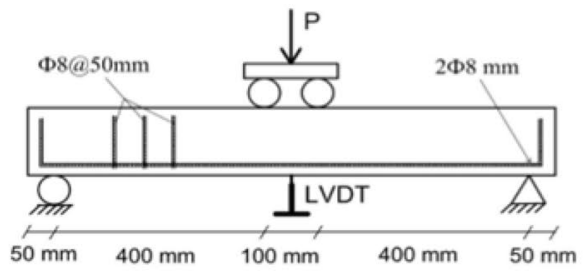

(b)

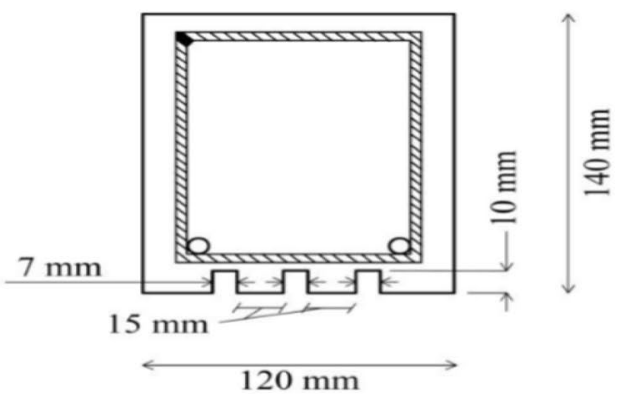

(e)

Fig. 5 Properties of experimental specimen used to verification of FEM anslysis of EBRIG and EBROG and the meshes of the model 
Table 3 Material properties of the verified beams (Mostofinejad and Shameli 2013)

\begin{tabular}{llllllll}
\hline$f_{c}^{\prime}(\mathrm{MPa})$ & $\begin{array}{l}\text { Steel bars tensile } \\
\text { yield stress (MPa) }\end{array}$ & $\begin{array}{l}\text { Ultimate tensile } \\
\text { stress bars (MPa) }\end{array}$ & $\begin{array}{l}\text { Tensile strength } \\
\text { fiber (MPa) }\end{array}$ & $\begin{array}{l}\text { Elastic modulus } \\
\text { fiber (GPa) }\end{array}$ & $\begin{array}{l}\text { Layer thickness } \\
\text { fiber (mm) }\end{array}$ & $\begin{array}{l}\text { Tensile strength } \\
\text { adhesive (MPa) }\end{array}$ & $\begin{array}{l}\text { The number of } \\
\text { layers of FRP }\end{array}$ \\
\hline 34.4 & 530 & 630 & 4100 & 230 & 0.12 & 45 & 1 \\
\hline
\end{tabular}

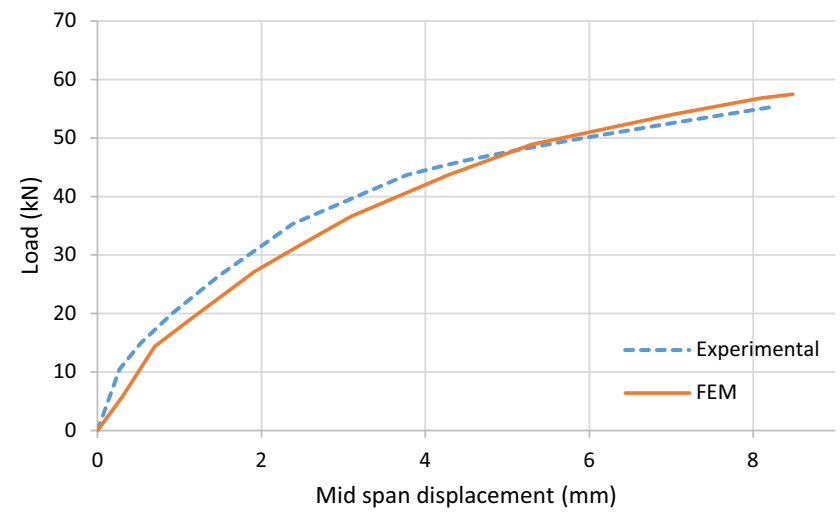

(b)

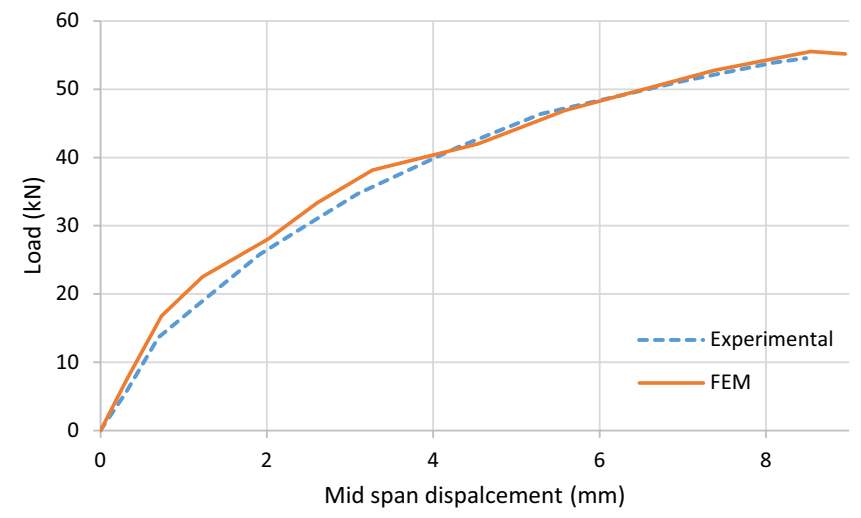

(a)

Fig. 6 Comparison of numerical and experimental load-displacement curve; a EBROG, b EBRIG specimen

it is necessary to use a specific element which is capable of modeling separation. Accordingly in ABAQUS the linear element called cohesive element could be applied. This element defines the behavior of the two surfaces against each other (ABAQUS 2013). The specific behavior of this element is defined based on the bond-slip stress relationship of the inter-layer surface in software. The cohesive element is between two different surfaces and thus it is capable of simulating the relationship between surfaces and calculating the relative displacement between them. The element may

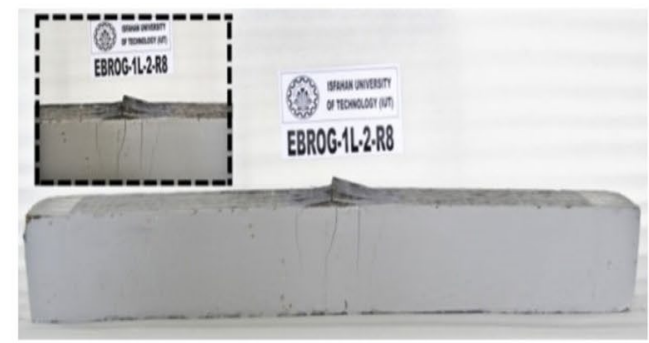

(a)

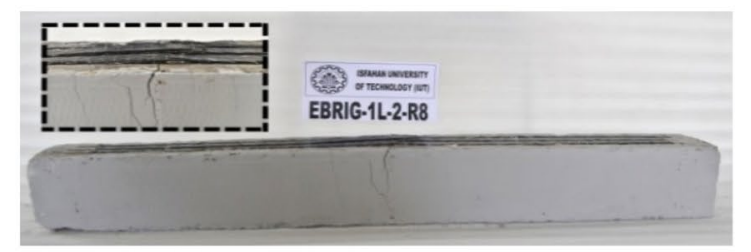

(c)

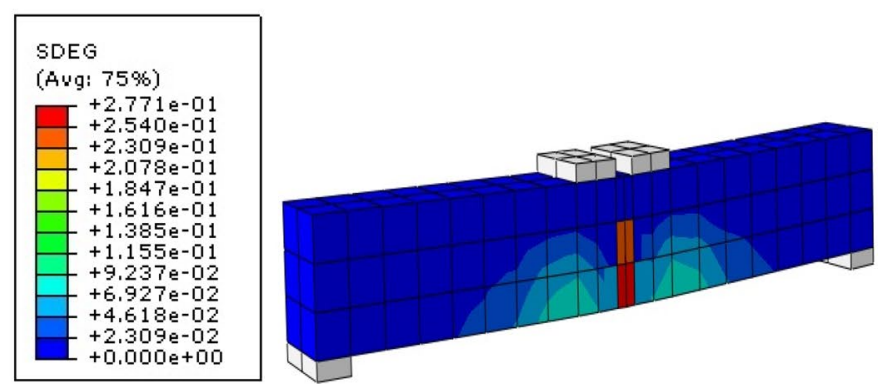

(b)

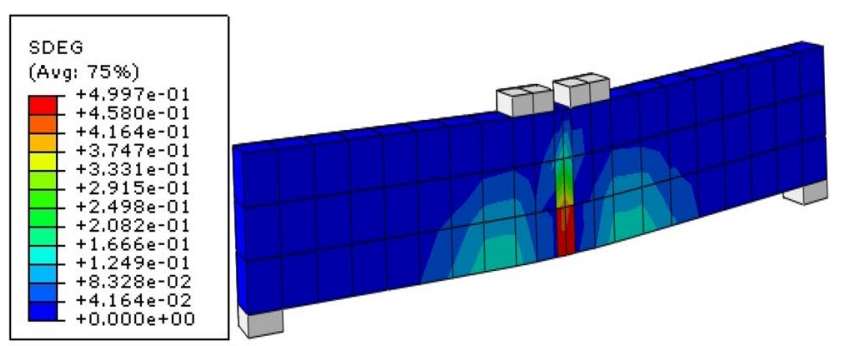

(d)

Fig. 7 Comparison of failure modes of strengthened beams in numerical and experimental test; a, b EBROG, c, d EBRIG 


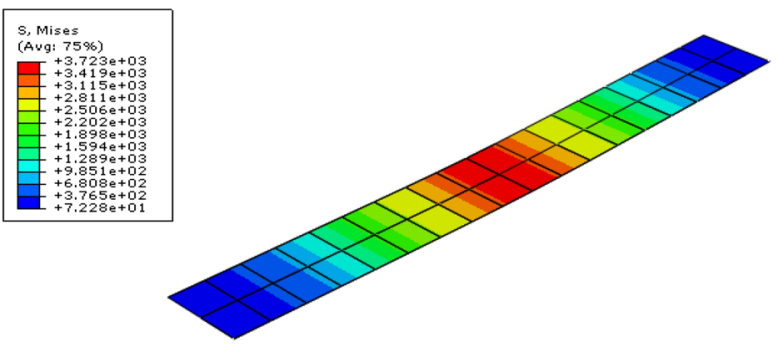

(b)

Fig. 8 Stress distribution in sheet FRP of models; a EBROG, b EBRIG

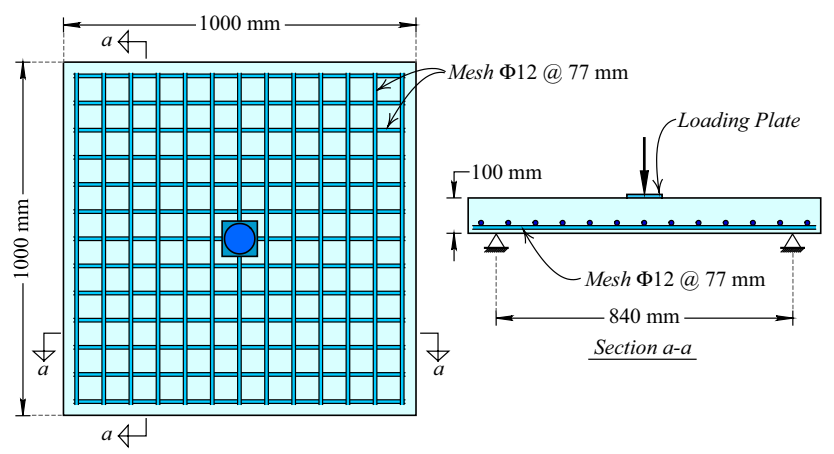

Fig. 9 Dimensions and reinforcements of samples

be composed of two parallel surfaces (the surfaces above and below the element) that are separated by a thickness. In order to model the inter-layer surface in the specimens strengthened by EBROG in groove location the shear-slip stress bond proposed by Fernando (Fernando 2010) was used and in the rest of surface the Lu model (2005) was applied to determine the cohesive element parameters. To simulate the inter-layer surface in EBRIG in the model the Lu model (2005) was applied either inside or outside the groove. The use of the proposed models is based on references (Hoseini 2009) and (Orooji 2014). It should be noted that in this paper the point cohesive element Coh3D8 with three displacement degree of freedom in each node was applied for inter-layer surface simulation in ABAQUS. In order to connect the inter-layer surface to the concrete and the strengthening sheet the bounded connection of elements is used. The mechanical properties of materials used in the modeled beams are expressed in Table 3 .

Figure 6 presents the load-displacement curve at the center of span for the models simulated in the software and the experimental specimens (both of them; EBRIG and EBROG strengthened beams) that the obtained values from

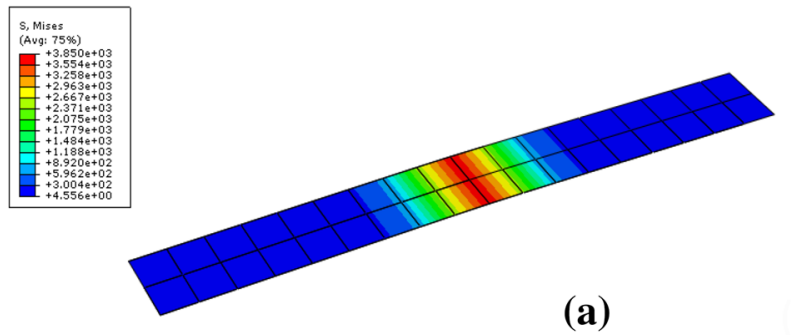

(a)

Table 4 Properties of concrete and steel (present study)

\begin{tabular}{llllll}
\hline & $\begin{array}{l}\text { Elastic } \\
\text { modulus } \\
(\mathrm{GP})\end{array}$ & $\begin{array}{l}\text { Poisson's } \\
\text { ratio }\end{array}$ & $\begin{array}{l}\text { Tensile } \\
\text { failure } \\
\text { stresses } \\
(\mathrm{MPa})\end{array}$ & $\begin{array}{l}\text { Crushing } \\
\text { failure } \\
\text { stresses } \\
(\mathrm{MPa})\end{array}$ & $\begin{array}{l}\text { Tensile } \\
\text { failure } \\
\text { stresses } \\
(\mathrm{MPa})\end{array}$ \\
\hline $\begin{array}{l}\text { Concrete } \\
\text { Steel }\end{array}$ & 25 & 0.2 & 3.5 & 28 & 3.5 \\
\hline
\end{tabular}

the numerical model and the experimental results are in a good agreement.

In Fig. 7 the bending failure with FRP sheet rupture was observed in the experimental and modeled specimens.

The maximum stress of the sheet in the final load bearing in the numerical model indicates the failure rupture mechanism of FRP in EBROG and EBRIG specimens as observed in Fig. 8.

\section{Models' definition and properties}

After validating of the modelling of control slab and the specimen strengthened by EBR method and validating FRP sticking "on" and "inside" the grooves in Sect. 2, the specimens of this study have been defined and analyzed. The size

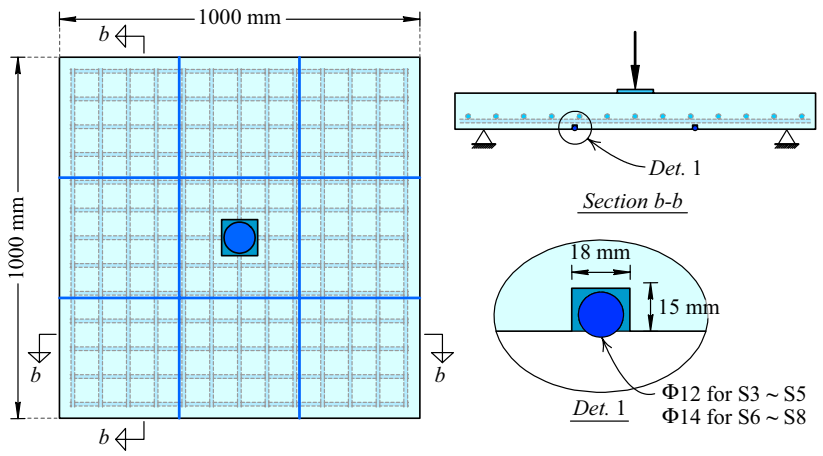

Fig. $10 \mathrm{~S} 1$ and S2 specimens (detail of strengthening) 
Fig. 11 Strengthening of slabs with external bonded rebars in one direction and EBR-FRP strips in another; a (S3 and S6), b (S4 and S7), c (S5 and S8)

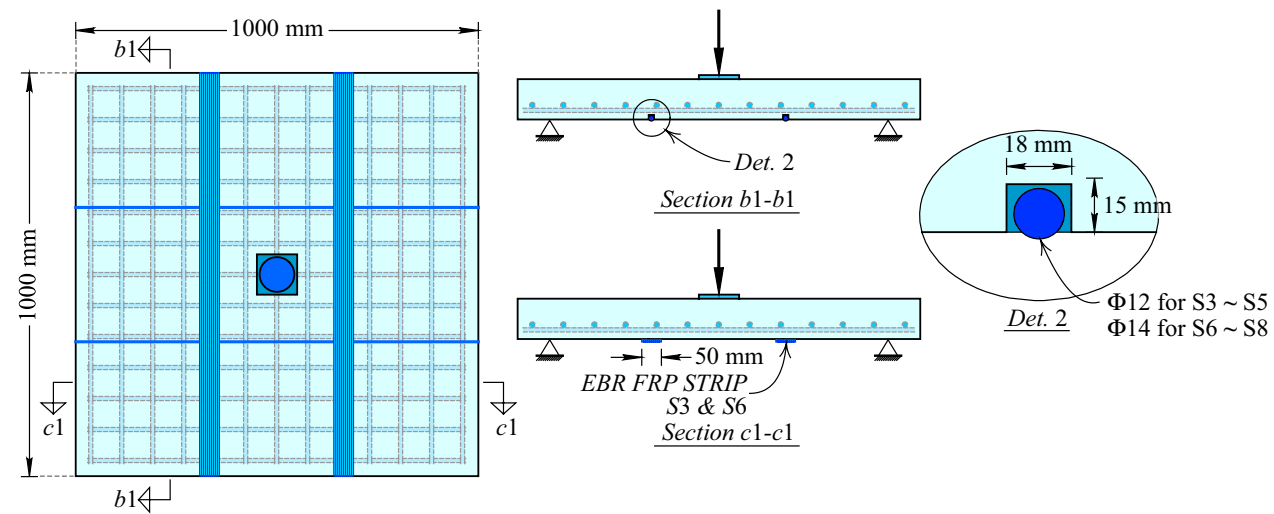

(a)
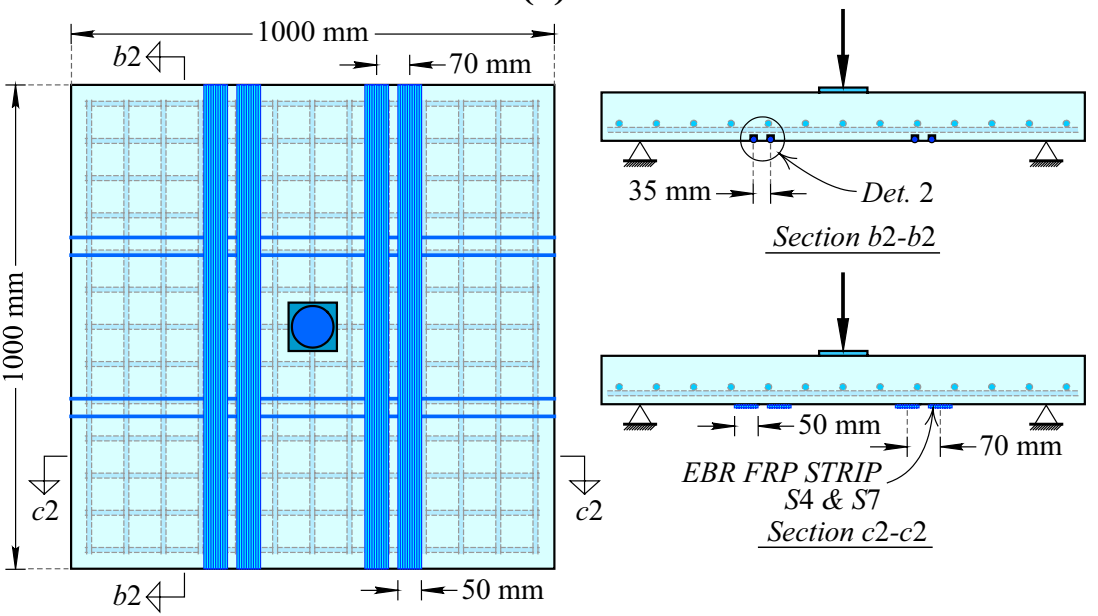

(b)
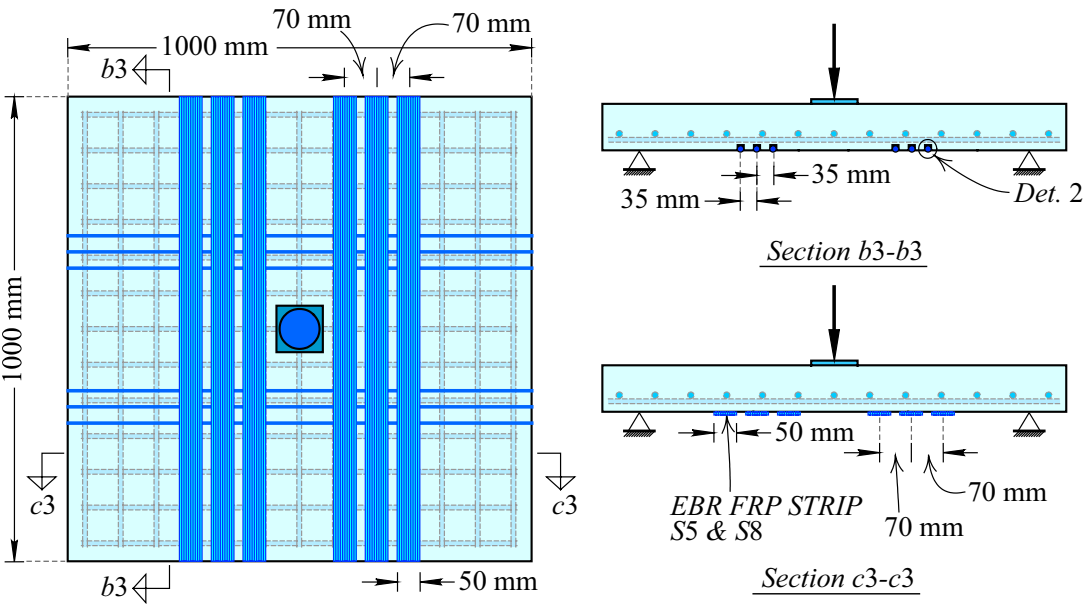

$\underline{\text { Section } b 3-b 3}$

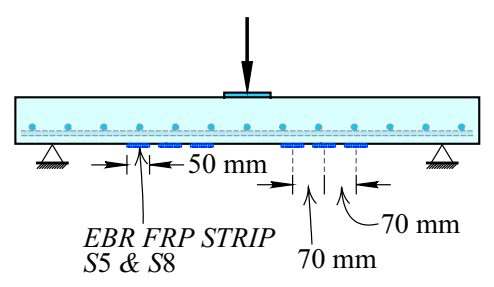

Section $c 3-c 3$

(c)

of slabs was $1000 \times 1000 \times 100 \mathrm{~mm}$ that a control specimen was without any strengthening versus the punching shear; 14 specimens were strengthened against punching shear by the following methods: in one direction the bar inside the grooves and in the other orthogonal direction FRP using EBR or EBROG were used for strengthening, and in all simulated models the maximum bending rebar was used for punching shear to occur (to prevention of flexural failure before punching shear failure). The slab plan and reinforcement cross section is shown in Fig. 9.

The applied steel and concrete properties are assumed as Table 4. The applied FRP composite is same as what shown in Table 2.

The modeled specimens are shown in Figs. 10, 11 and 12. The specimens $\mathrm{S} 1$ and $\mathrm{S} 2$ were strengthened by one sticked bars under the slab at each side of loading point 
Fig. 12 Strengthening of slabs with external bonded rebars in one direction and EBROG-FRP strips in another; $\mathbf{a}$ ( $\mathrm{S} 9$ and $\mathrm{S} 12), \mathbf{b}$ (S10 and S13), c (S11 and S14)
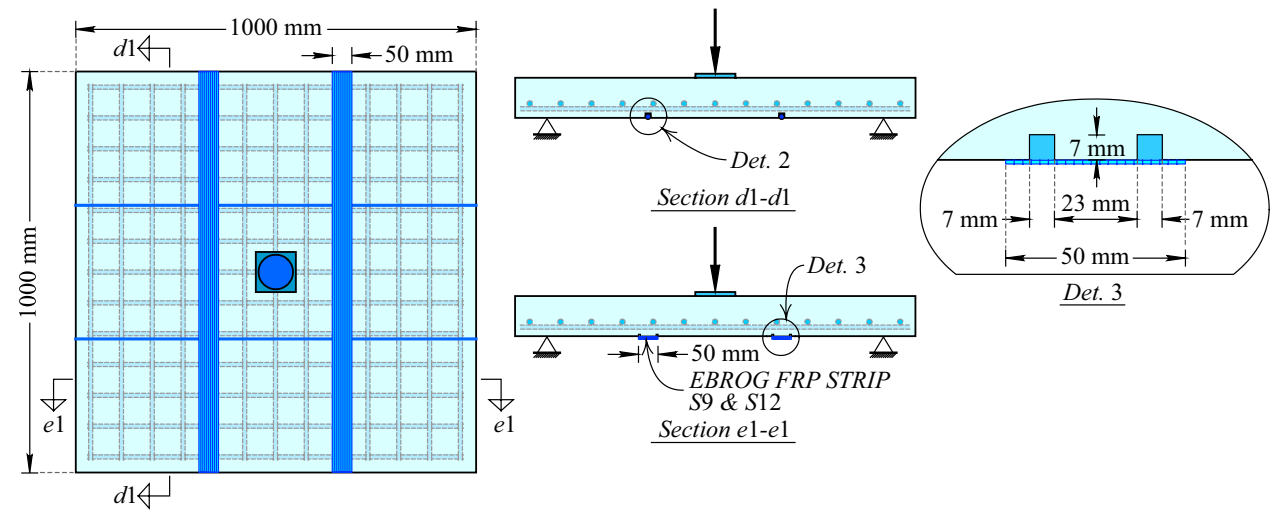

(a)
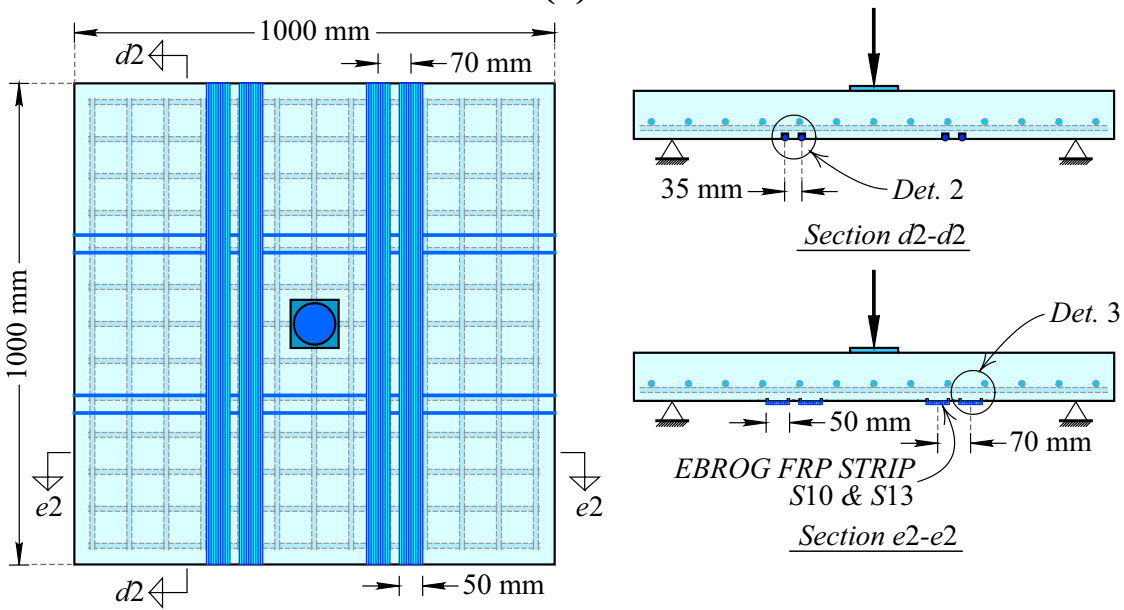

(b)
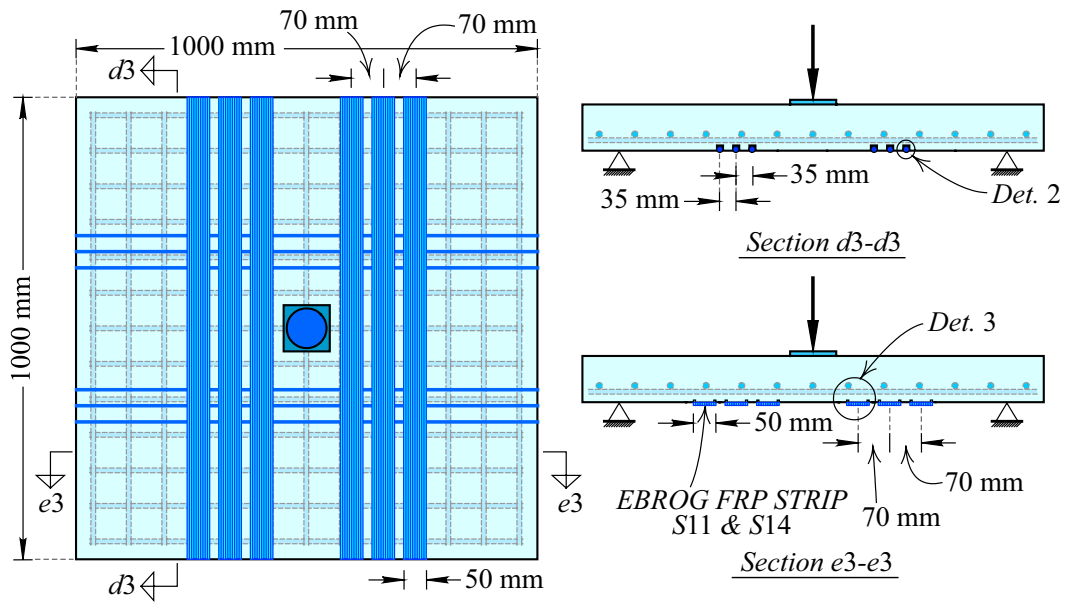

Section $d 3-d 3$

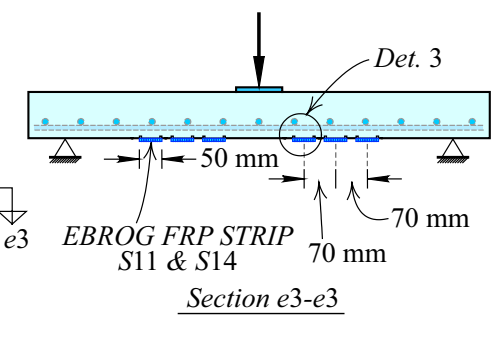

(c)
(Fig. 10). Specimens S3-S8 strengthened with 1 or 2 or 3 sticked bars at each face of loading point in one direction and 1 or 2 or 3 EBR-FRP strip(s) at each side of loading point in another orthogonal direction (Fig. 11). Specimens S9 to S14 (Fig. 12) were similar to those of S3 to S8, with the difference that the FRP was installed in these specimens with EBROG method (2 grooves under each strip). The other detailed properties of 15 specimens are shown in Table 5.

\section{Results of specimens nonlinear analysis}

The specimens were modeled and analyzed after definition and the addressed results included: failure form, load-displacement curve, the area under load-displacement curve, and strain in the reinforcement and FRP sheet. The numerical results are presented in Table 6. Also in Figs. 13, 14, $15,16,17,18$ and 19, load-displacement curves, damaged 
Table 5 Properties of the samples were analyzed

\begin{tabular}{llllllllllllllll}
\hline & S & S1 & S2 & S3 & S4 & S5 & S6 & S7 & S8 & S9 & S10 & S11 & S12 & S13 & S14 \\
\hline $\begin{array}{l}\text { The diameter } \\
\text { of the rebar }\end{array}$ & - & 12 & 14 & 12 & 12 & 12 & 14 & 14 & 14 & 12 & 12 & 12 & 14 & 14 & 14 \\
in the groove \\
$(\mathrm{mm})$
\end{tabular}

elements, internal bars strain distribution, sticked bars strain distribution, maximum external sticked bars strain-displacement curve, EBR and EBROG FRP sheets strain have been shown.

Figure 17 shows the strain of external sticked bars at the middle of bar length against to mid span displacement for several bars in the vicinity of the columns numbered 1, 2, and 3. For example in S4 specimen, 1 and 2 are for first and second external bars, considering that in this sample, 2 external reinforcements were used at each side of loading pint.

It should be noted that the nonlinear analysis was stopped when the failure was occurred. To check the failure in FEM analysis, the strain in compressive face of concrete compared to 0.003 checked and also the strain in internal and external sticked bars and FRP sheets and damaged elements were examined.

With regards to Table 6 in the non-strengthened specimen $\mathrm{S}$ the behavior is totally shear according to Figs. 10-a and 11-specimen $S$ and after reaching the maximum load bearing capacity, it is decreased with a sharp drop which indicates the rupture caused by punching shear in the slab. In the specimens S1 and S2 (specimens strengthened by bar inside the groove by EBRIG method) the punching shear capacity is increased by 28 and $32 \%$ based in Table 6 and by the strengthening the punching shear range is shifted from around the loading plate to the external zone which enlarged the punching shear cone and increases the punching shear capacity (Fig. 11, specimens $\mathrm{S} 1$ and S2). As it is presented in Fig. 12-a none of the longitudinal bars of the specimens

Table 6 Numerical results

\begin{tabular}{|c|c|c|c|c|c|c|c|c|c|}
\hline Name & Failure load (KN) & Failure form & S.b.s. ${ }^{a}$ & E.s.b.s. ${ }^{b}$ & F.b. ${ }^{c}$ & $\mathrm{~A}^{\mathrm{d}}$ & I.r. $^{\mathrm{e}}(\%)$ & C.p. ${ }^{f}$ & C..$^{g}$ \\
\hline $\mathrm{S}$ & 128.7 & Shear & 0.0018 & - & - & 276 & - & -0.003 & -0.003 \\
\hline $\mathrm{S}_{1}$ & 164.8 & Shear & 0.0019 & 0.002 & - & 362 & 28 & -0.0028 & -0.003 \\
\hline $\mathrm{S}_{2}$ & 171.4 & Shear & 0.0019 & 0.0022 & - & 403 & 33 & -0.0032 & -0.0032 \\
\hline $\mathrm{S}_{3}$ & 152.2 & Shear & 0.002 & 0.002 & Debonding -0.0076 & 416.5 & 18 & -0.0023 & -0.0033 \\
\hline $\mathrm{S}_{4}$ & 154.5 & Shear & 0.002 & 0.0021 & Debonding -0.0079 & 438.1 & 20 & -0.0027 & -0.0035 \\
\hline $\mathrm{S}_{5}$ & 194.3 & Shear-flexure & 0.002 & 0.0026 & Debonding -0.0137 & 1130.4 & 51 & -0.0041 & -0.0041 \\
\hline $\mathrm{S}_{6}$ & 164.4 & Shear & 0.002 & 0.002 & Debonding -0.0075 & 447.8 & 27 & -0.0024 & -0.0032 \\
\hline $\mathrm{S}_{7}$ & 166.8 & Shear & 0.002 & 0.0021 & Debonding -0.0081 & 463.7 & 30 & -0.0022 & -0.0033 \\
\hline $\mathrm{S}_{8}$ & 197.1 & Shear-flexure & 0.002 & 0.0027 & Debonding -0.0139 & 1216 & 53 & -0.0041 & -0.0041 \\
\hline $\mathrm{S}_{9}$ & 159.3 & Shear & 0.002 & 0.002 & Debonding -0.0089 & 479 & 23 & -0.0022 & -0.003 \\
\hline $\mathrm{S}_{10}$ & 170.5 & Shear & 0.002 & 0.0021 & Debonding -0.0091 & 488.5 & 32 & -0.0025 & -0.0031 \\
\hline $\mathrm{S}_{11}$ & 200.9 & Shear-flexure & 0.002 & 0.0027 & Rupture-0.0165 & 1204.3 & 56 & -0.0041 & -0.0041 \\
\hline $\mathrm{S}_{12}$ & 167.3 & Shear & 0.002 & 0.0021 & Debonding -0.0094 & 530 & 30 & -0.0024 & -0.003 \\
\hline $\mathrm{S}_{13}$ & 177.3 & Shear & 0.002 & 0.0021 & Debonding -0.0099 & 516 & 37 & -0.0026 & -0.0031 \\
\hline $\mathrm{S}_{14}$ & 209 & Shear-flexure & 0.002 & 0.0027 & Rupture -0.0165 & 1305.1 & 62 & -0.0041 & -0.0041 \\
\hline
\end{tabular}

${ }^{\mathrm{a}} \mathrm{Slab}$ bar strain at Failure

${ }^{\mathrm{b}}$ External sticked bars strain at failure

${ }^{c}$ FRP behavior and FRP strain at failure

${ }^{\mathrm{d}}$ Area of under load-displacement curve $(\mathrm{kN}-\mathrm{m})$

${ }^{\mathrm{e}}$ Strength increase ratio \%

${ }^{\mathrm{f}}$ Concrete compressive strain at peak of curve

${ }^{\mathrm{g}}$ Concrete compressive strain at the failure 


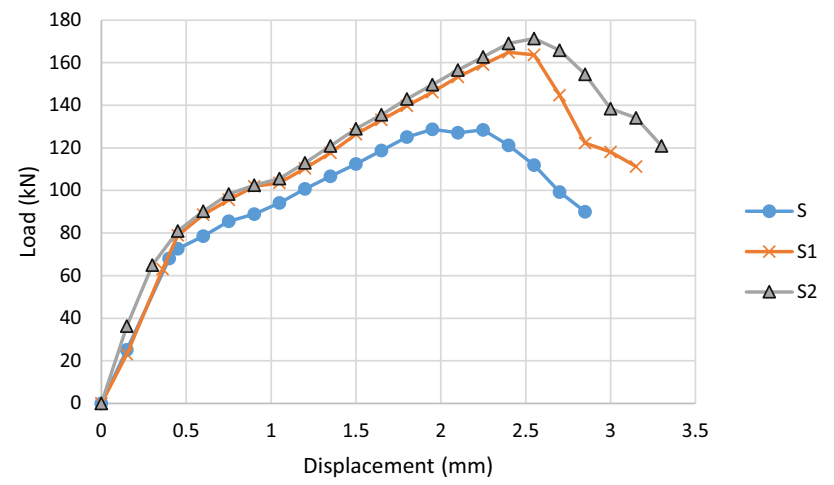

(a)

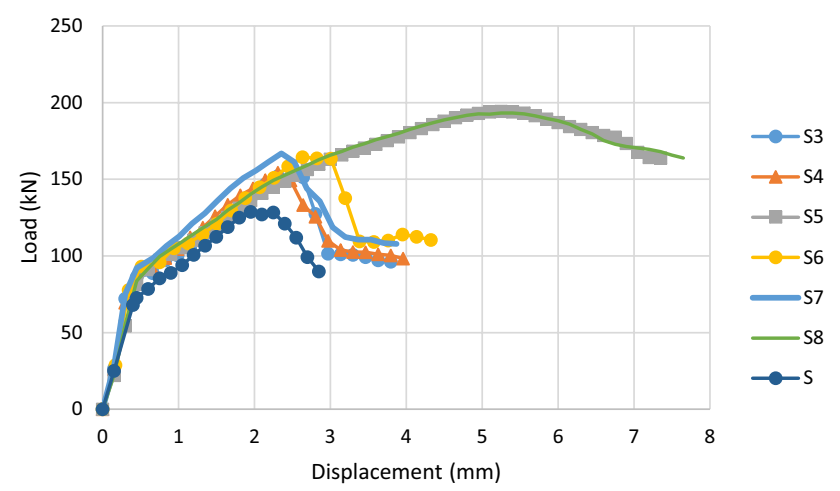

(b)

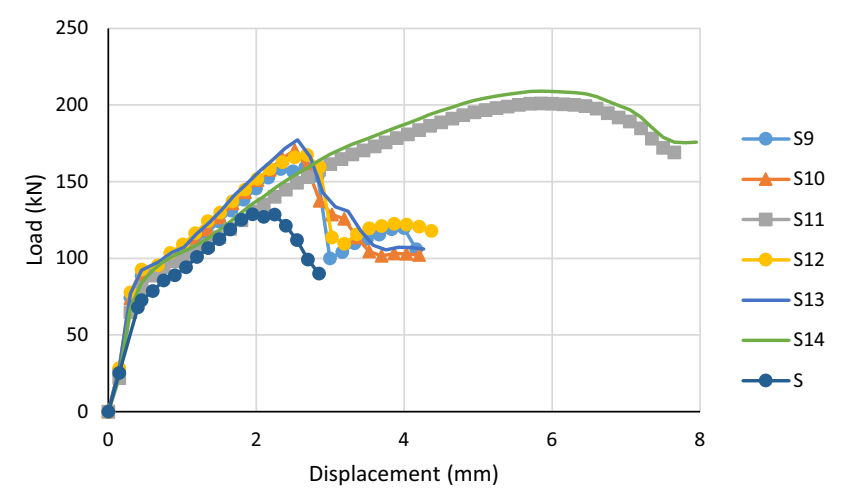

(c)

Fig. 13 Load-displacement relationship for slabs: a reinforced with rebar by EBROG, b reinforced with rebar by EBROG and FRP by EBR, $\mathbf{c}$ reinforced with rebar by EBROG and FRP by EBROG

are yielded and amounts if tensile reinforcement strain are close to 0.002 related to the yield threshold of steel. In Fig. 13-specimens S1 and S2) and 14 the bars inside the groove of $\mathrm{S} 1$ and $\mathrm{S} 2$ specimens have 0.002 or higher strain which indicates that the strengthening method has led to the yielding of the bars inside the grooves. After reaching the punching shear capacity in specimens S1 and S2 and creating punching shear fracture in them, since the concrete has no more load-bearing strength, the load is transferred to the bars. The load is split among the bars and causes them to yield. In these two specimens, the area under load-displacement curve increased 31 and $46 \%$ respectively.

In S3-S8 specimens strengthened by bar inside the groove by EBRIG in one direction ( $x$ or $y$ ), and FRP by EBR in other direction ( $y$ or $x$ ) the punching shear capacity is increased by $18-53 \%$. In S5 and S8 specimens with the increased punching shear capacity of 51 and 53\% the punching shear zone is shifted to the outside of the strengthened zone which increases the shear capacity of the slab and shear to bending change in behavior Fig. 11. Strain in the bars at the center of the slab in these specimens is 0.002 which indicates that the strengthening has led to the yield of longitudinal bars and increased load bearing capacity of the slab (Fig. 12-b). The strain of reinforcements inside the grooves in these specimens has reached the yield level and in the S5 and S8 specimens it is beyond yielding and reached 0.0026 and 0.0027 which indicates shear to bending change in behavior (Figs. 13, 14). Considering the amount of FRP strain in Table 6 in S3-S8 specimens there were debonding rupture mechanism of FRP sheet (Fig. 15).

In S9-S14 specimens strengthened by bar inside the groove by EBRIG and FRP by EBROG the punching shear capacity is increased by $23-62 \%$. The maximum punching shear capacity is in S11 and S14 specimens with the increased punching shear capacity of 56 and $62 \%$ (Table 6). In this way, it is observed that in both strengthened groups (S3-S8 and S9-S14), with increasing number of sticked bars and FRP strips, punching shear capacity of slabs has been increased. The punching shear zone is shifted to the outside of the strengthened zone which increases the shear capacity of the slab and shear to bending change in behavior in the current group (Fig. 11). Strain in the bars at the center of the slab in these specimens is 0.002 which indicates that the strengthening has led to the yield of longitudinal bars and increased load bearing capacity of the slab (Fig. 12-c). The strain of reinforcements inside the grooves in these specimens has reached the yielding level and in the S11 and S14 specimens it is beyond yielding and reached 0.0027 which indicates shear to bending change in behavior (Figs. 13, 14). Considering the amount of FRP strain level of 0.0165 in Table 6 in S11-S14 specimens there were FRP rupture (Fig. 15) and debonding occurred in the rest of specimens (Fig. 16). EBROG method had 15-25\% increase in strain in FRP sheet compared to the EBR method (Table 6; Fig. 16).

In two group of strengthened specimens ( $\mathrm{S} 3-\mathrm{S} 8$ and S9-S14), in a constant thickness of FRP sheet, the load bearing capacity of specimens, increased from 18 to 51 and 27 to $53 \%$ compared to control specimen respectively 

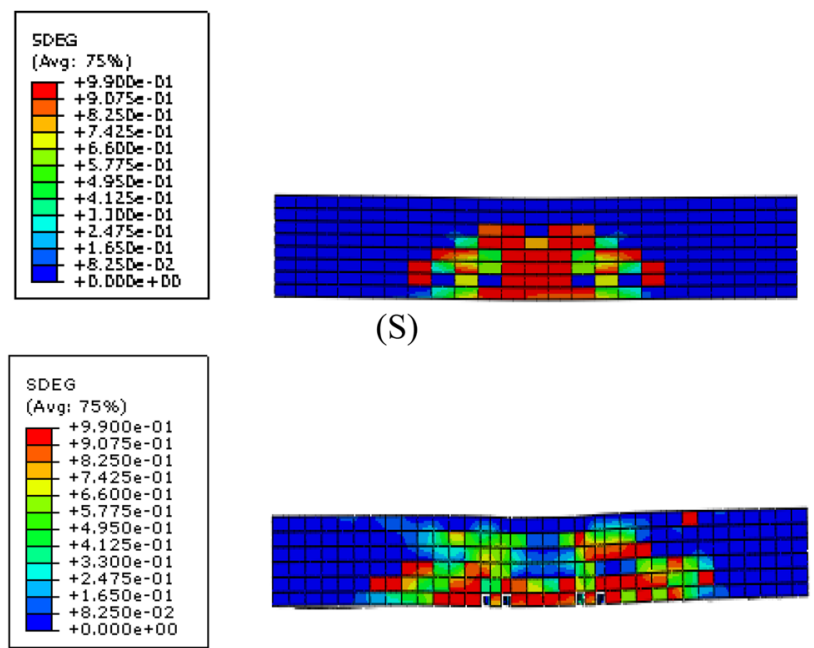

$(\mathrm{S} 3, \mathrm{~S} 6)$

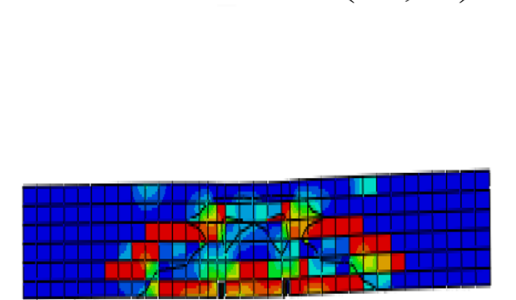

(S9, S12)
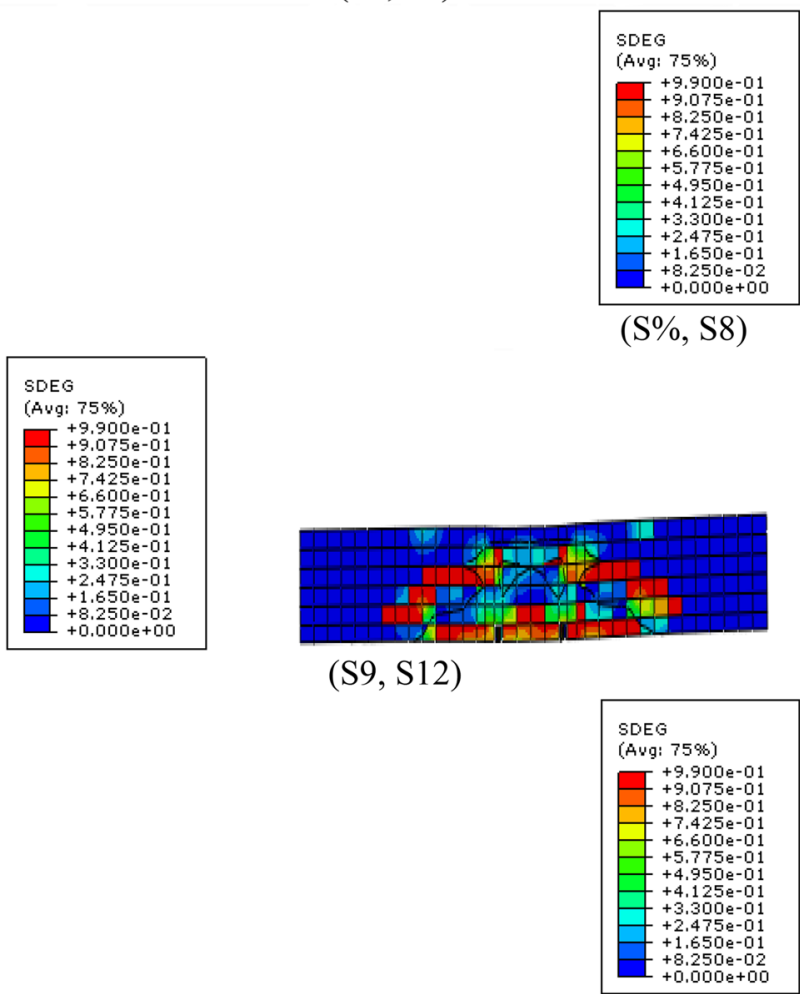

(S11, S14)

Fig. 14 Range of damaged elements in the specimens

by increasing in the number of FRP sheets and external sticked bars at each side of column.

Also in the similar specimens with EBROG compared to EBR strengthened specimens, the FRP strain at failure and the load bearing capacity increase, on average increased about 21 and $22 \%$. This can be described as the effect of the grooving method.
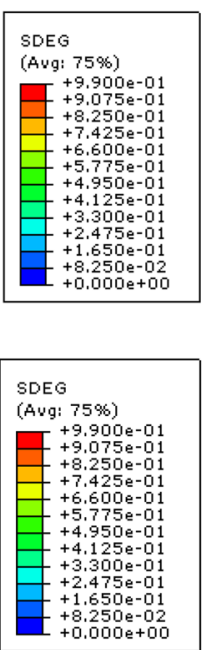

$+8.250 \mathrm{e}-02$
$+0.000 \mathrm{e}+00$

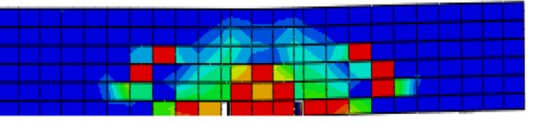

$(\mathrm{S} 1, \mathrm{~S} 2)$

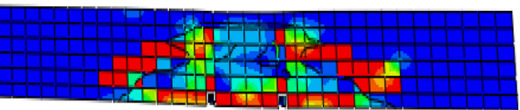

$(\mathrm{S} 4, \mathrm{~S} 7)$
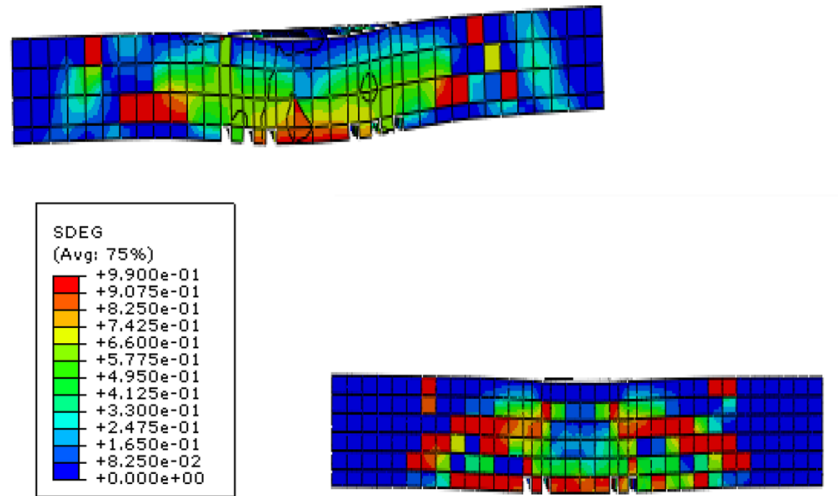

$(\mathrm{S} 10, \mathrm{~S} 13)$

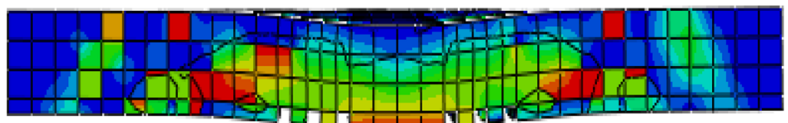

Table 6 also shows that in all specimens the concrete compressive strain, reached to or beyond of $0.003\left(\varepsilon_{\mathrm{cu}}\right)$.

With respect to the values of Table 6 , it is seen that the area below the load-displacement curve in the first group samples has been added an average of $38 \%$. This increase has been about $148 \%$ and $173 \%$ for second and third groups respectively. The maximum of this increase has 


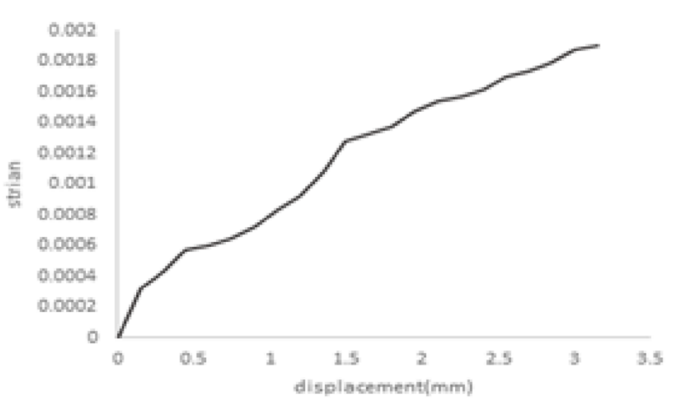

(a)
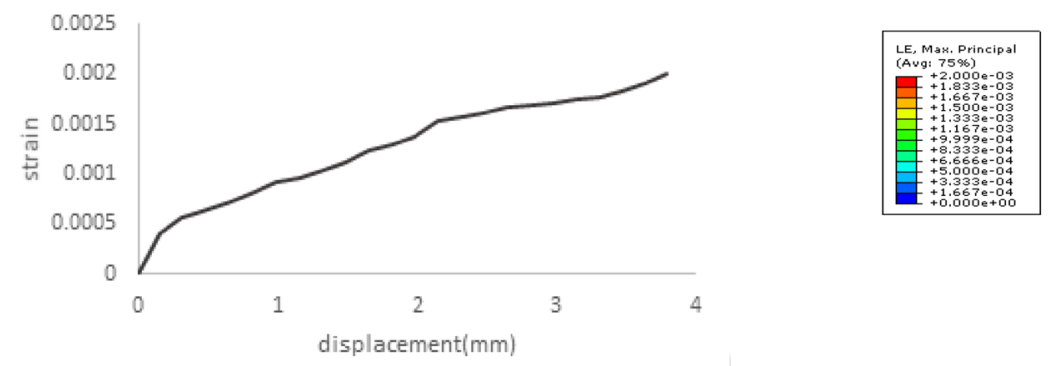

(b)
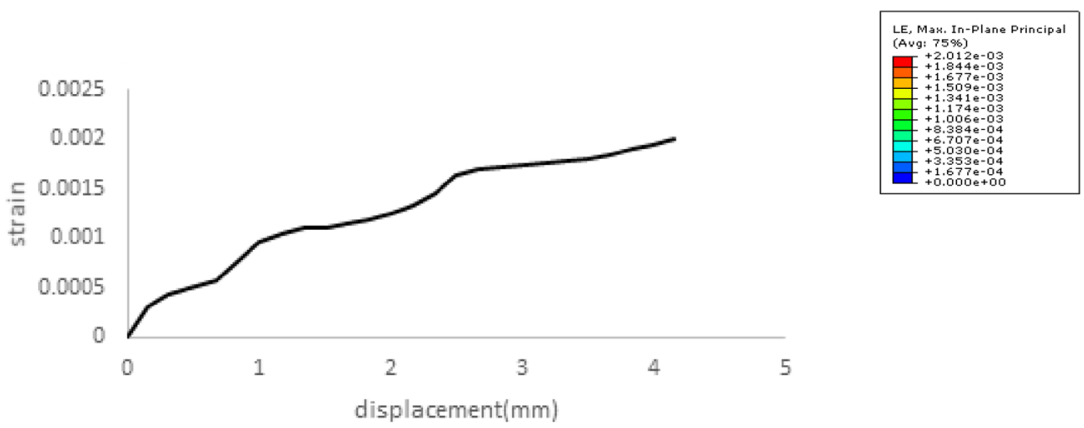
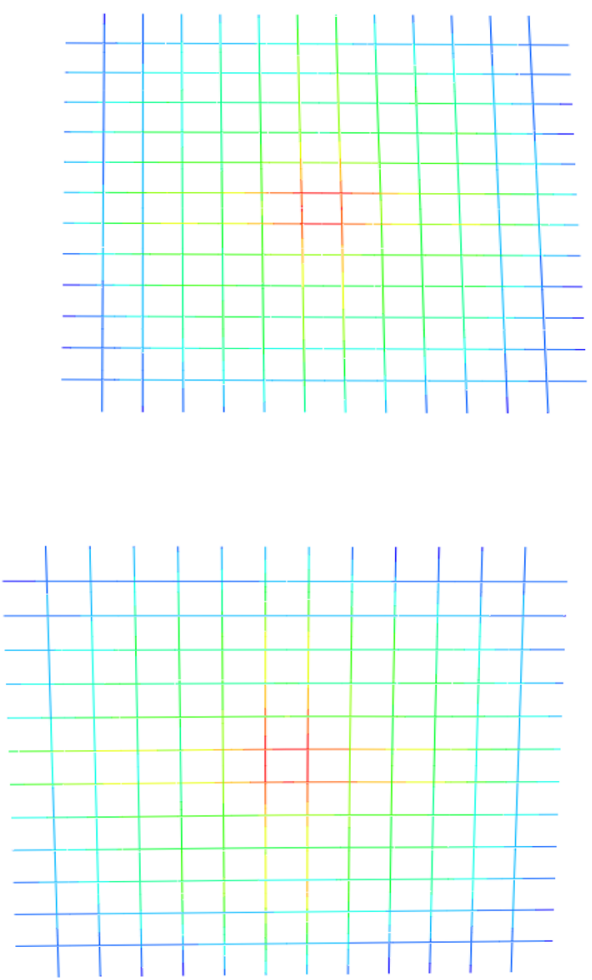

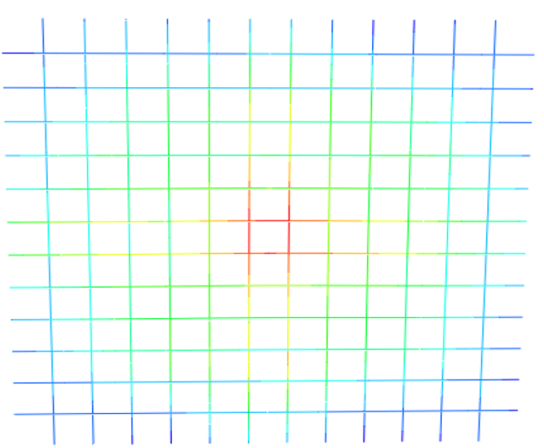

(c)

Fig. 15 The strain distribution in slab reinforcement and reinforcement strain-displacement graph; a (S1, S2) samples, b (S3, S4, S5, S6, S7, S8) samples, c (S9, S10, S11, S12, S13, S14) samples

been occurred in S5 and S11 specimens in which there are three strips of FRP on each side of the column for reinforcement (in S5 with EBR and S11, EBROG method). It is noted that the area under the load-displacement curve is expressed as an important index of the slab behavior in the energy absorption.

\section{Summary and conclusions}

In this study to strengthen flat slabs against the punching shear, the grooving technique and EBRIG method is used for the bar and the EBROG and EBR methods are applied for the FRP sheets. For this purpose 15 numerical models are simulated all of which were slabs with dimensions 
International Journal of Advanced Structural Engineering (2019) 11:79-95

91

$(\mathrm{S} 1, \mathrm{~S} 2)$

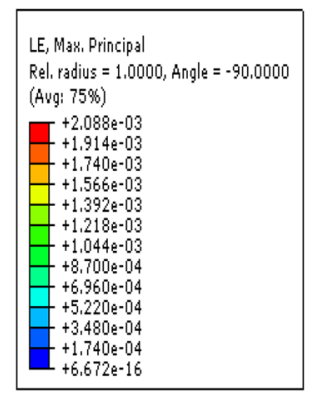

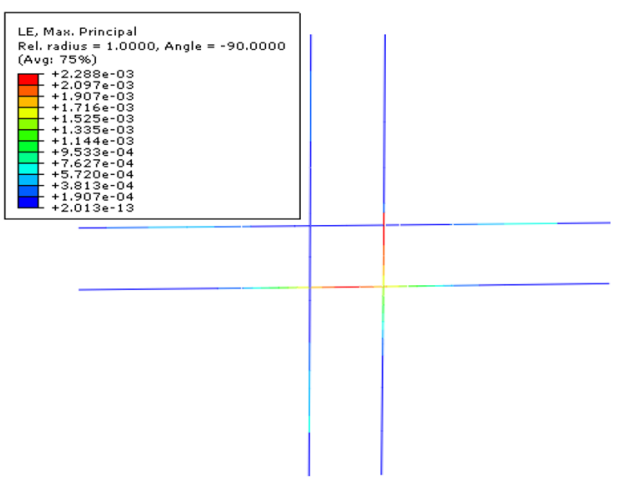
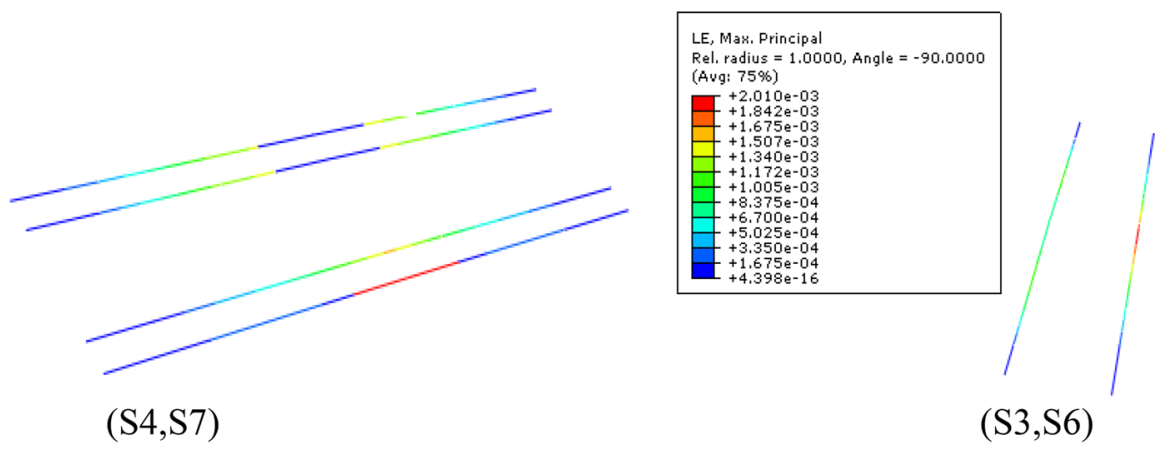
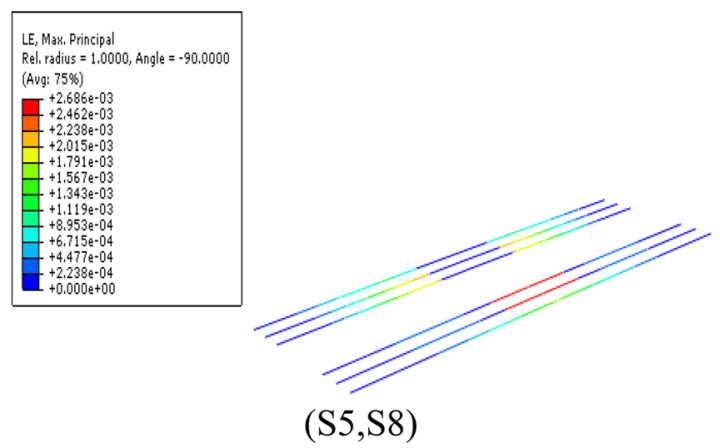

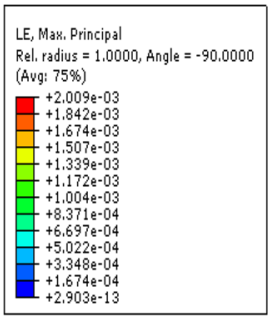

$(\mathrm{S} 9, \mathrm{~S} 12)$

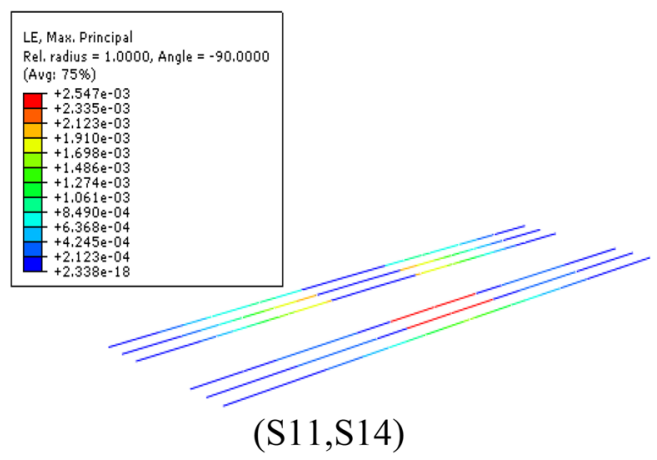

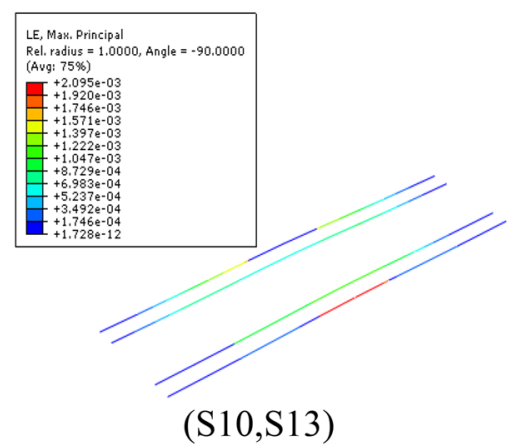

Fig. 16 The strain distribution in the sticker in groove rebars

Springer 


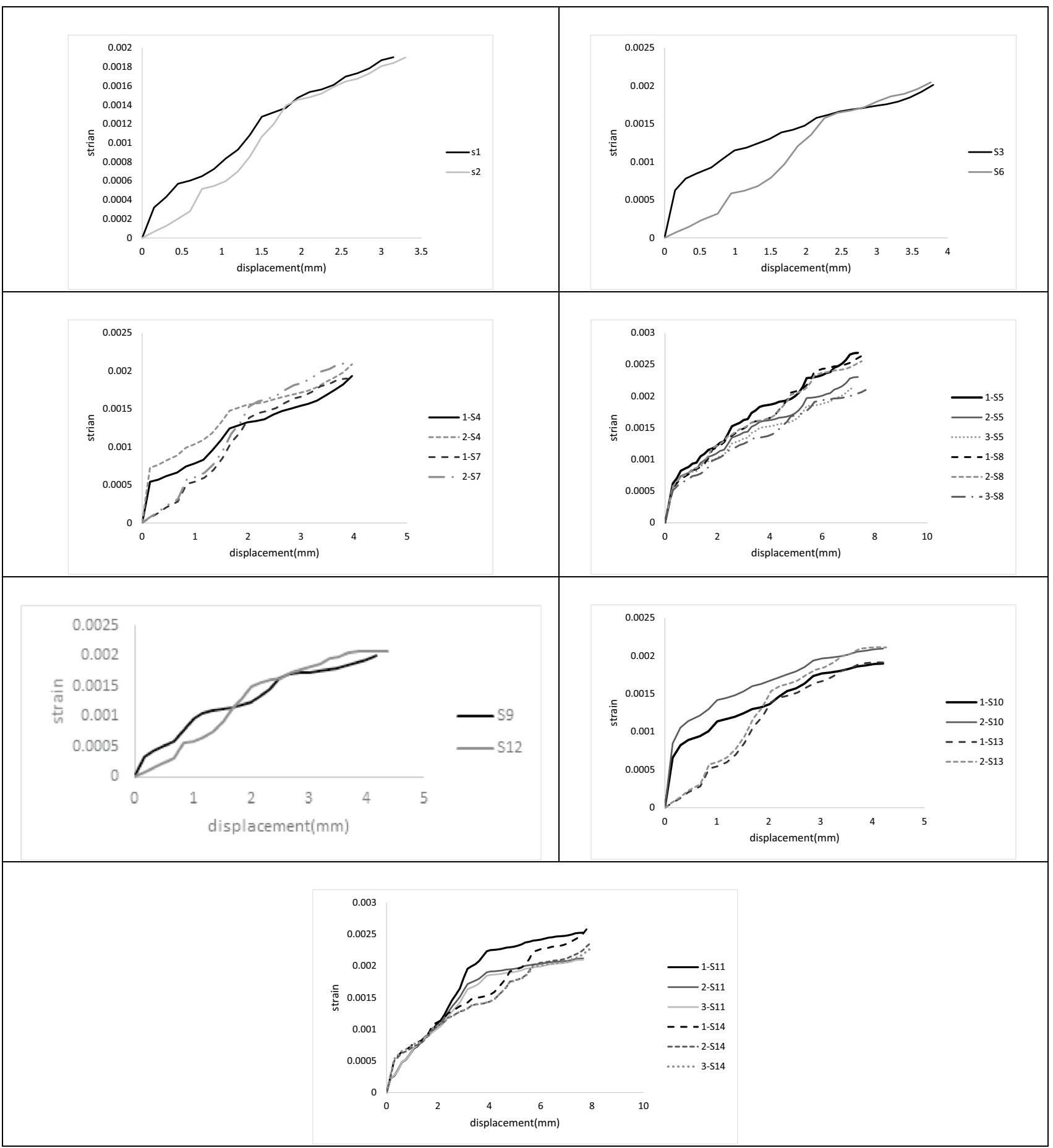

Fig. 17 Strain-displacement relationship for external sticked rebars

$1000 \times 1000 \times 100 \mathrm{~mm}$ that included a control specimen without any shear reinforcement against punching shear; 14 specimens are strengthened against the punching shear by the mentioned method. According to research method first the experimental specimens of other researchers including non-reinforced and reinforced slab by EBR and strengthening by EBRIG method have been validated. The following results are obtained after defining and analyzing the specimens:

- In the validation of the unreinforced and reinforced slab and grooving, the nonlinear analysis could assess unre- 


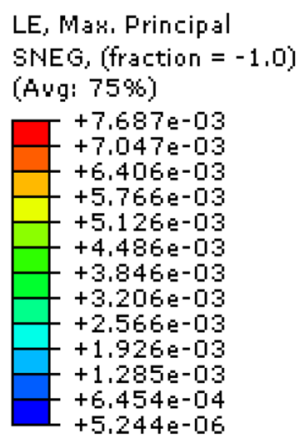

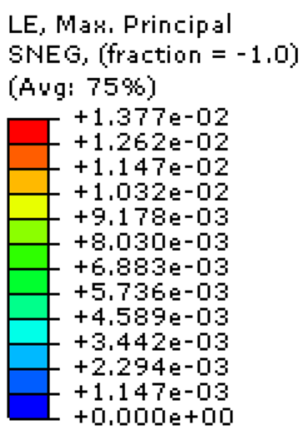

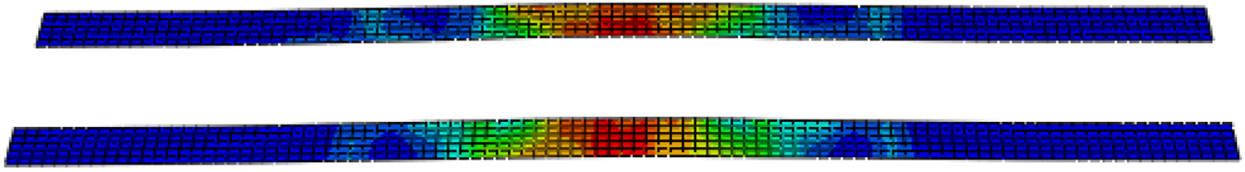

$(\mathrm{S} 3, \mathrm{~S} 6)$

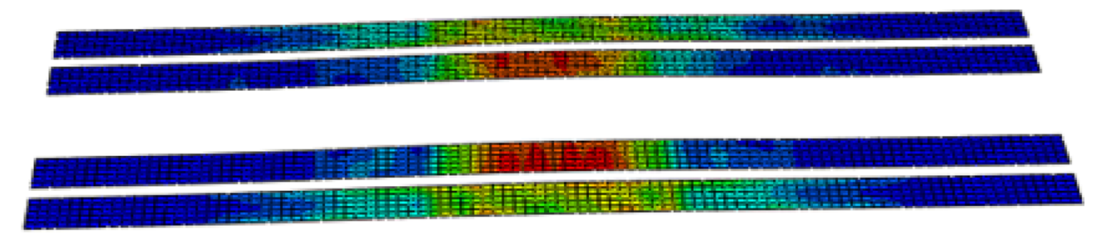

$(\mathrm{S} 4, \mathrm{~S} 7)$

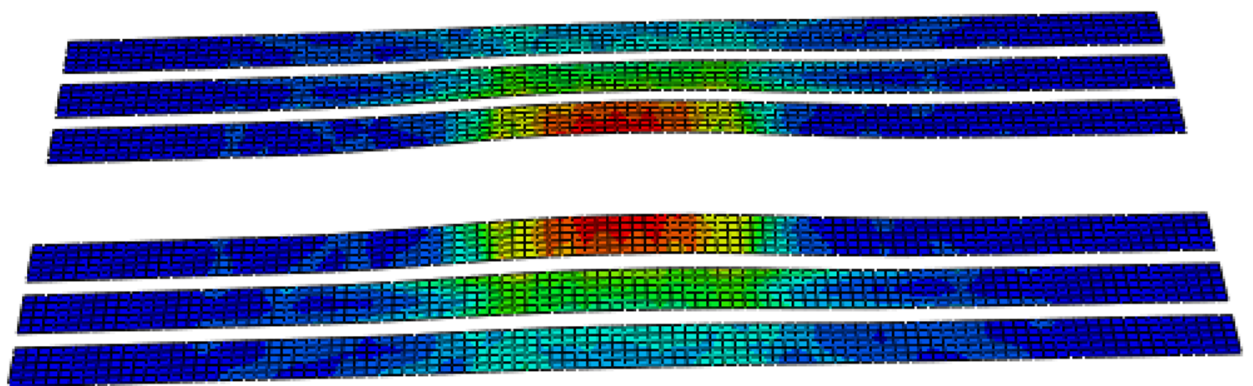

$(\mathrm{S} 5, \mathrm{~S} 8)$

Fig. 18 Strain distribution in length of FRP sheets (EBR)

inforced and reinforced slab and evaluate results of such as failure load, load-displacement curve and the form of cracks.

- In the slab reinforced with the bar inside the groove by EBRIG in two directions, $28 \%$ and $33 \%$ increase in punching shear capacity (with two different diameters of the external bars attached to the groove) was observed.
- In slabs reinforced with the bar inside the groove in one direction and FRP in the other direction by EBR, 18-53\% increase in shear capacity was observed. Changes in the rate of increase are due to changes in the external bar diameter and FRP thickness.

- In slabs reinforced with the bar inside the groove in one direction and FRP in the other direction by EBROG, $23-62 \%$ increase in shear capacity was observed. 

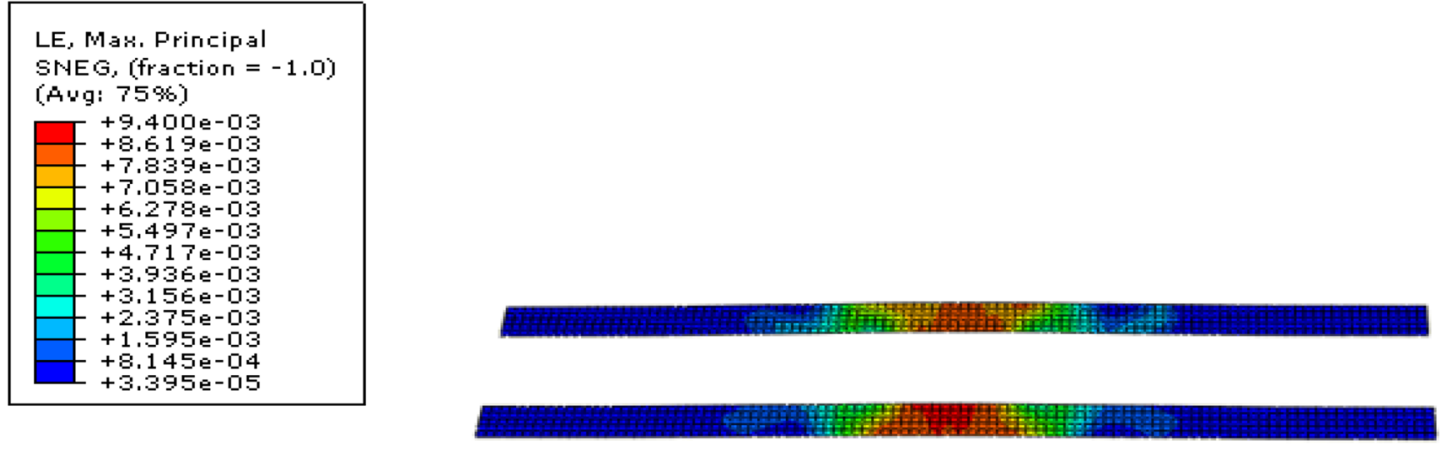

$(\mathrm{S} 9, \mathrm{~S} 12)$
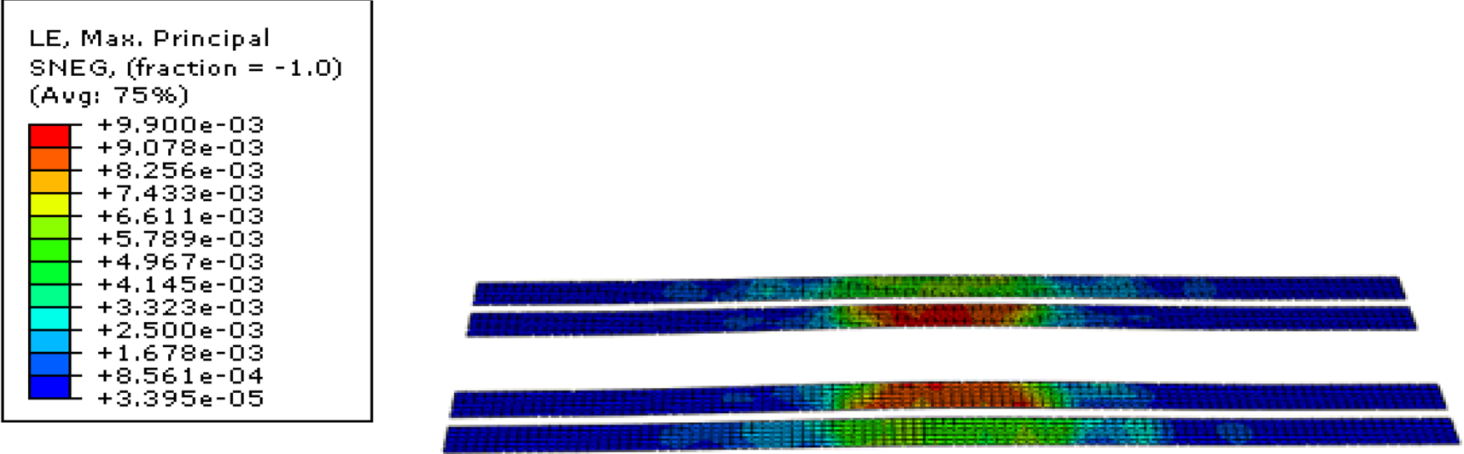

$(\mathrm{S} 10, \mathrm{~S} 13)$
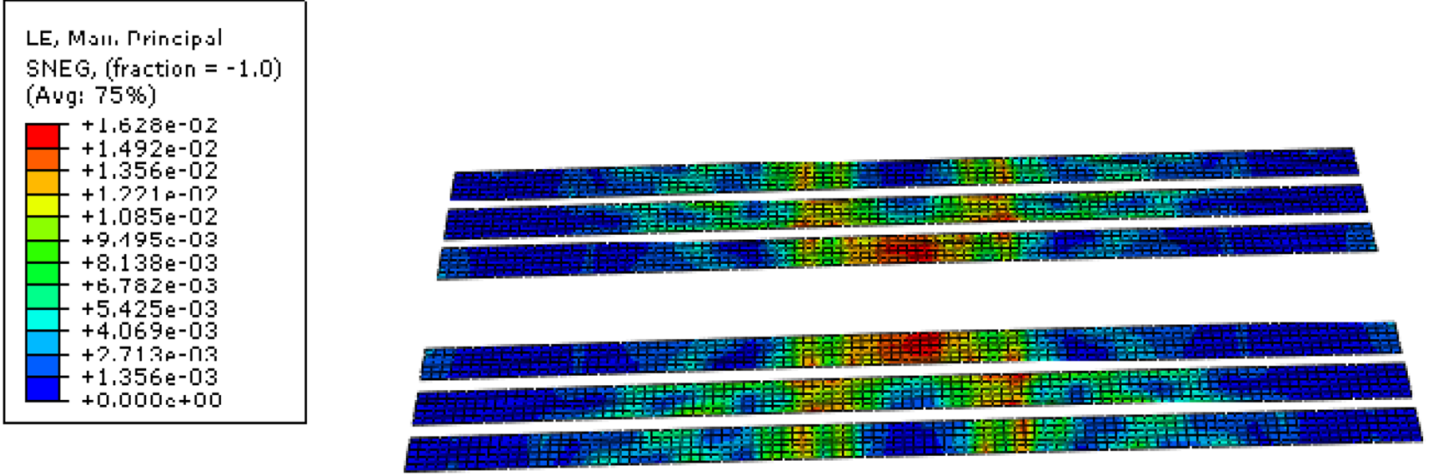

$(\mathrm{S} 11, \mathrm{~S} 14)$

Fig. 19 Strain distribution in length os FRP sheets (EBROG)

Changes in the rate of increase are due to changes in the bar diameter and FRP sheet thickness.

- Type of failure in reinforced specimens by EBR was premature FRP debonding from the concrete surface and this mode of failure shows that in EBR it is not possible to use the FRP sheet bearing capacity fully because before FRP reaches its final capacity, it is separated from the concrete surface. This result has also been reported by other researchers. 
- The specimens reinforced by EBROG had $15-25 \%$ increase in strain in FRP sheet compared to the EBR method and in specimens that the number of grooves is increased FRP was ruptures. Therefore EBROG shearing method is more efficient than the EBR surface mounting method.

- In the strengthened specimens, the area under load-displacement curve has increased between 38 and $170 \%$.

Open Access This article is distributed under the terms of the Creative Commons Attribution 4.0 International License (http://creativecommons.org/licenses/by/4.0/), which permits unrestricted use, distribution, and reproduction in any medium, provided you give appropriate credit to the original author(s) and the source, provide a link to the Creative Commons license, and indicate if changes were made.

\section{References}

ABAQUS Inc. (2013) ABAQUS/theory user manual, Version 6.13

ACI (American Concrete Institute) (2014) ACI 318-2014: building code requirements for structural concrete (ACI 318-99) and Commentary (318-08). American Concrete Institute, Farmington Hills

Agbossou A, Michel L, Lagache M, Hamelin P (2013) Strengthening slabs using externally bonded strip composite: analysis of concrete on the strengthening. Compos Part B 39:1125-1135

Binici B, Bayark O (2003) Punching shear strengthening of reinforced concrete flat plates using carbon fiber reinforced polymers. J Struct Eng ASCE 129(9):1173-1182

Ebead U, Marzouk H (2002) Strengthening of two-way slabs subjected to moment and cyclic loading. ACI Struct J 99(3):435-444

El-Salakawy Ehab F, Polak Maria Anna, Soudki A (2003) New shear strengthening technique for concrete slab-column connections. ACI Struct J 100(3):297-304

Fernando D (2010) Bond behaviour and debonding failures in CFRPstrengthed steel members. PhD thesis, The Hong Kong Polytechnic University

Hajihashemi A, Mostofinejad D, Azhari M (2011) Investigation of RC beams strengthened with prestressed NSM CFRP laminates. J Compos Construct 15(6):887-895
Harajli M, Soudki A (2003) Shear strengthening of interior slab-column connections using fiber-reinforced polymer sheets. J Compos Construct ASCE 7(2):145-153

Hoseini SJ (2009) Modeling of FRP-concrete interface debonding in strengthened reinforced concrete beams with some case studies. M.Sc. Thesis, Isfahan University of Technology, Isfahan, IRAN

Lu XZ, Teng JG, Ye LP, Jiang JJ (2005) Bond-slip models for FRP sheets/plates bonded to concrete. Eng Struct 27(6):920-937

Megally S, Ghali A (1994) Design considerations for slab-column connection in seismic zones. ACI Struct J 91(3):303-313

Meisami H, Mostofinejad D, Nakamura H (2012) Punching shear strengthening of two-way flat slabs using CFRP rods. Compos Struct 99:112-122

Meisami H, Mostofinejad D, Nakamura H (2014) Strenghthening of flat slabs with FRP fan for punching shear. Compos Struct 119:305-314

Menetrey P (2002) Synthesis of punching failure in reinforced concrete. Cement Concr Compos 24:497-507

Mostofinejad D, Hajrasouliha MJ (2011) Investigation of effective factors on the performance of grooving method to prevent debonding of FRP sheets from concrete surface. Civil Eng J Ferdosi Univ Mashhad 22(2):47-57

Mostofinejad D, Mahmoudabadi E (2010) Grooving as alternative of surface preparation to postpone debonding of FRP lamination in concrete beams. J Compos Construct 14(6):804-811

Mostofinejad D, Shameli SM (2013) Externally bonded reinforcement in grooves (EBRIG) technique to postpone debonding of FRP sheets in strengthened concrete beams. Constr Build Mater 38:751-758

Orooji M (2014) Numerical modelling of externally bonded in groove (EBRIG) method for adhering FRP sheets to concrete beams. M.Sc. Thesis, Isfahan University of Technology, Isfahan, Iran

Park R, Paulay T (2009) Reinforced concrete structures. Wiley, Haboken

Sharaky IA, Torres L, Baena M, Mias C (2012) An experimental study of different factors affecting the bond of NSM FRP bars in concrete. Compos Struct 99:350-365

Publisher's Note Springer Nature remains neutral with regard to jurisdictional claims in published maps and institutional affiliations. 